Article

\title{
Performance Improvement of a Grid-Connected Inverter under Distorted Grid Voltage Using a Harmonic Extractor
}

\author{
Sungjoon Cho ${ }^{1}$, Ho-Sung Kang ${ }^{2}$, Kyo-Beum Lee ${ }^{2}$ (I) and Ji-Yoon Yoo ${ }^{1, *}$ \\ 1 School of Electrical Engineering, Korea University, Seoul 02841, Korea; csj1391@ajou.ac.kr \\ 2 Department of Electrical and Computer Engineering, Ajou University, 206, World cup-ro, Yeongtong-gu, \\ Suwon 16499, Korea; fgrtoy11@ajou.ac.kr (H.-S.K.); kyl@ajou.ac.kr (K.-B.L.) \\ * Correspondence: jyyoo@korea.ac.kr; Tel.: +82-2-923-9200
}

Received: 18 August 2019; Accepted: 14 September 2019; Published: 16 September 2019

\begin{abstract}
This paper introduces an improved current control strategy for a grid-connected inverter system operating under distorted grid voltage conditions. Although existing current controllers for grid-connected inverters have proportional integral gains with suitable bandwidth, low-order harmonic components can be generated by distorted grid voltages. The proposed improved current controller is established in a synchronous reference frame that rotates at harmonic frequency. The input signals for the harmonic current controller should contain only the specific harmonic components requiring suppression. Therefore, the proposed current controller uses a harmonic extractor to distinguish current signals from fundamental and specific harmonic components. The harmonic extractor retains only the relevant harmonic components for individual current controllers with high harmonic signal ratios. This paper introduces two different strategies to extract specific harmonic components for the current controller. The proposed control strategy does not require any additional hardware filter circuits and can be implemented easily by designing a suitable digital filter. When using the proposed method, grid current quality is significantly improved compared to conventional methods that do not include harmonic extractors. The effectiveness of the proposed method is verified through simulations and practical experiments.
\end{abstract}

Keywords: harmonic extractor; distorted voltage; grid-connected inverter; harmonic current controller; harmonic signal ratio

\section{Introduction}

Renewable energy sources, such as wind turbines, solar cells, and fuel cells, have been adopted to reduce greenhouse gas emissions compared to the use of fossil fuels. Greenhouse effects can cause climate change and severe environmental damage. A number of renewable energy generation systems have been implemented recently to reduce $\mathrm{CO}_{2}$ emissions according to international agreements [1]. Distributed generation systems based on renewable energy require grid-connected inverters to extract maximum power from various energy sources. This application area requires only one-directional power control functionality to transfer energy to utility systems.

Based on the widespread adoption of renewable power systems, various energy storage systems (ESSs) using batteries have been installed to maintain a balance between power generation and load conditions [2]. Grid-connected inverters for ESSs must have bi-directional power control functionality to charge or discharge battery systems according to power demands and reduce harmonic components for battery life cycles. Therefore, sophisticated current control strategies must be developed to manage power flow in both directions and to retain the harmonics of the grid current [3-7]. 
Utility suppliers require renewable generation systems that provide high-quality current, even when voltage is unbalanced due to faults or distorted by nonlinear loads. Droop control schemes and positive sequence power-based control methods have been adopted to improve grid stability under grid voltage imbalances [8-10].

The total harmonic distortion of grid-connected inverter output current should be maintained under $5 \%$ during normal operating conditions according to the IEEE-1547 standard [11]. Although grid impedance differs based on point of common coupling (PCC) characteristics, grid-connected inverters should still attempt to satisfy this criterion. Various types of current control methods have been introduced to achieve high-performance current control characteristics. Controllers using hysteresis, proportional integral (PI) control, and proportional resonant (PR) control have been established as common current controllers for grid-connected inverters [12]. Hysteresis controllers can maintain a high-quality current with very little ripple, but a high switching frequency is necessary to maintain a suitable current quality [13]. Furthermore, the switching frequency varies according to the current hysteresis band, and it is difficult to design output filters for inverter systems based on hysteresis controllers. PI controllers in synchronous reference frames are effective for maintaining a high-quality current with a constant switching frequency. Synchronous reference frames rotating at the fundamental frequency of the grid voltage allow AC current controllers to function like DC components. This means that a PI controller with the proper bandwidth can achieve the steady state error rate of zero for required current commands in a synchronous reference frame [14,15]. A PR controller in a stationary reference frame is another method for maintaining high-quality current in a grid-connected inverter [16-18]. The ideal PR controller has infinite gain for specific frequency components and can be implemented with a constant switching frequency in a stationary reference frame [19].

When a grid-connected inverter has been installed at a site, there are many practical issues to be solved. Different grid and operating conditions such as distorted voltage, grid impedance and nonlinear load generate undesirable harmonics of the grid current. Additionally, higher-order harmonics by switching frequency or electro-magnetic interference from other equipment also deteriorate the current waveform. Therefore, not only an individual harmonic compensator but also a proper signal processing strategy are necessary to suppress the specific frequency component effectively.

Several methods have been introduced to suppress the sub-order harmonics of grid current [15, 20-23]. One compensation method for reducing grid current harmonics uses the Cauchy-Schwarz inequality theory [23]. The harmonic components of grid voltage are required to find the minimum point of the grid current total harmonic distortion (THD). Therefore, grid current quality is dependent on the accurate detection of voltage harmonics. Whenever the harmonic components of grid voltage change, the operating point for minimizing current THD must be adjusted. Additionally, the algorithm for finding the proper operating point requires significant pre-calculation time.

Repetitive controllers have been introduced to maintain a high-quality grid current using simple configurations [24-26]. A repetitive controller performs similarly to a large number of resonant controllers. However, even though repetitive controllers have a positive effect in terms of suppressing harmonic components, traditional repetitive controllers incur long delay times, which can lead to poor dynamic response characteristics. According to a previous study on repetitive controllers [25], the dynamic response time to step changes in a reference current is greater than $100 \mathrm{~ms}$, which is very slow compared to other existing controllers. Furthermore, this method does not limit the THD value of grid current to below 5\%, as stipulated in the IEEE 1547 standard. Although the compensation methods discussed above are all able to improve the quality of the grid current, they have drawbacks in terms of the increased calculation time, slow dynamic responses, complex controller configurations, etc.

This paper proposes an improved current controller for sub-order harmonic components (e.g., fifth and seventh). The proposed controller for reducing sub-order harmonics is introduced in a synchronous reference frame rotating at the fifth or seventh frequency to make AC harmonic components behave like DC components. The proposed control method also uses a harmonic extractor to obtain a specific harmonic current after transforming output currents into a synchronous reference 
frame. These procedures are implemented using embedded software without any additional hardware requirements. Therefore, the proposed method can be easily adopted in traditional current control systems. The proposed configuration can detect specific harmonic components for suppression compared to the conventional compensator using a signal that contains other different sub-order harmonics. These characteristics improves current controller performance in terms of retaining the amplitude of special frequency harmonics below a certain level. The proposed compensation method is suitable to solve practical issues after commissioning inverters in the field.

The remainder of this paper is organized as follows. In Section 2, the characteristics of each order of harmonic current caused by distorted grid voltages are analyzed using the symmetrical coordinates method. Section 3 introduces two types of current controllers using a total harmonic extractor (THE) and selected harmonic extractor (SHE), respectively. The novelty can be emphasized using a harmonic signal ratio, as shown in Section 3. Various simulations and comparison are carried out to prove the stable operation of the proposed method in Section 4. The effectiveness of the proposed THE and SHE methods is verified based on both simulations and practical experiments in Sections 4 and 5. Finally, Section 6 presents the conclusions of this study.

\section{Analysis of Harmonic Currents}

Figure 1 presents a block diagram of the proposed grid-connected inverter with harmonic compensation. The control system consists of a phase-locked loop, coordinate transformation operation, PI controller for fundamental frequencies, and harmonic current controller for reducing specific components. The harmonic currents generated by nonlinear loads lead to grid voltage distortion.

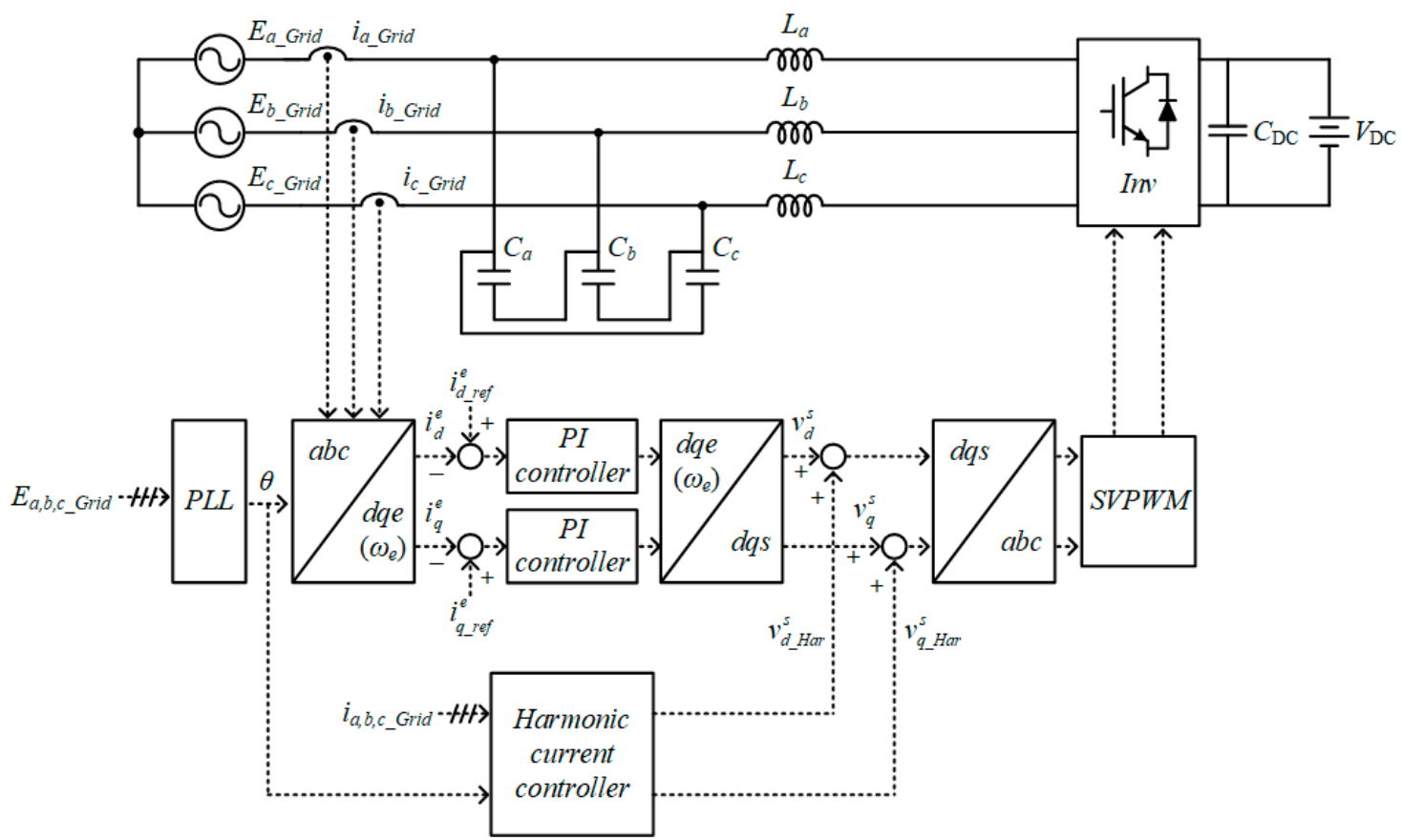

Figure 1. Block diagram of current control strategy with harmonic compensation method. PI: proportional integral. PLL: phase locked loop. SVPWM: space vector pulse width modulation

To analyze the characteristics of harmonic currents, the output current of a three-phase inverter can be expressed using a Fourier transform as follows: 


$$
\begin{aligned}
& i_{a_{-} \text {Grid }}=\sum_{h=1,5,7 \ldots}^{\infty} I_{h} \times \sin \left(h \omega_{e} t\right) \\
& i_{b_{-} \text {Grid }}=\sum_{h=1,5,7 \ldots}^{\infty} I_{h} \times \sin \left[h\left(\omega_{e} t-\frac{2 \pi}{3}\right)\right] \\
& i_{c_{-} \text {Grid }}=\sum_{h=1,5,7 \ldots}^{\infty} I_{h} \times \sin \left[h\left(\omega_{e} t+\frac{2 \pi}{3}\right)\right]
\end{aligned}
$$

Among the outputs of the inverter, if the three-phase currents show balanced characteristics, the multiples of third harmonics can be eliminated in the $d q$ synchronous frame. On the other hand, the fundamental frequency currents and harmonic currents such as seventh and 13th can be expressed as the following sequence in the $a b c$ coordinate system:

$$
i_{a_{-} \text {Grid_Fun }}=I_{1} \times \sin \omega_{e} t, i_{b_{-} \text {Grid_Fun }}=I_{1} \times \sin \left(\omega_{e} t-\frac{2 \pi}{3}\right), i_{c_{-} \text {Grid_Fun }}=I_{1} \times \sin \left(\omega_{e} t+\frac{2 \pi}{3}\right)
$$

As shown in Equation (2), the three-phase currents are displaced by an $a b c$-phase sequence. In other words, the relationships between each phase current have the characteristics of a positive sequence. However, the harmonics have negative sequence components as well (e.g., fifth, 11th, and 17th), which can be expressed as follows:

$$
i_{a_{-} G r i d_{\_} 5 t h}=I_{5} \times \sin 5 \omega_{e} t, i_{b_{-} G r i d_{-} 5 t h}=I_{5} \times \sin \left(5 \omega_{e} t+\frac{2 \pi}{3}\right), i_{c_{-} G r i d_{-} 5 t h}=I_{5} \times \sin \left(5 \omega_{e} t-\frac{2 \pi}{3}\right)
$$

From Equations (1)-(3), one can see that the output currents of the inverter have different sequence characteristics according to different orders, as shown in Table 1 [27]. Each controller for harmonic compensation must be designed considering these properties to suppress individual harmonic components effectively.

Table 1. Sequence of harmonic currents.

\begin{tabular}{cc}
\hline Categories & Order \\
\hline Positive sequence & 1st, 7 th, 13 th,$\cdots$ \\
Negative sequence & 5th, 11th, 17th, $\cdots$ \\
Zero sequence & 3rd, 9th, 15th, $\cdots$ \\
\hline
\end{tabular}

\section{Harmonic Compensation Method}

\subsection{Conventional Compensation Method}

The conventional compensation method is popular based on its control simplicity and performance. As shown in Figure 2, this method utilizes only a coordinate transformation operation, low pass filters (LPF), and PI controllers to reduce harmonic components effectively without using any complicated calculations or additional hardware components. The fifth and seventh harmonic components of the grid current are converted from AC values in a stationary reference frame into DC values in a synchronous reference frame by using a coordinate transformation operation. Each reference angular velocity $\left(-5 \omega_{e}\right.$ and $\left.7 \omega_{e}\right)$ is selected by considering the negative or positive sequence characteristics of the harmonic current. Before an input enters the PI controller, it is necessary to remove fundamental frequency components and other high-order components, except for specific frequencies (e.g., fifth or seventh), as shown in Figure 2. The other components, including the fundamental frequency in the synchronous reference frame, are attenuated by the LPF to transform the input signals for the PI controller into DC values. 


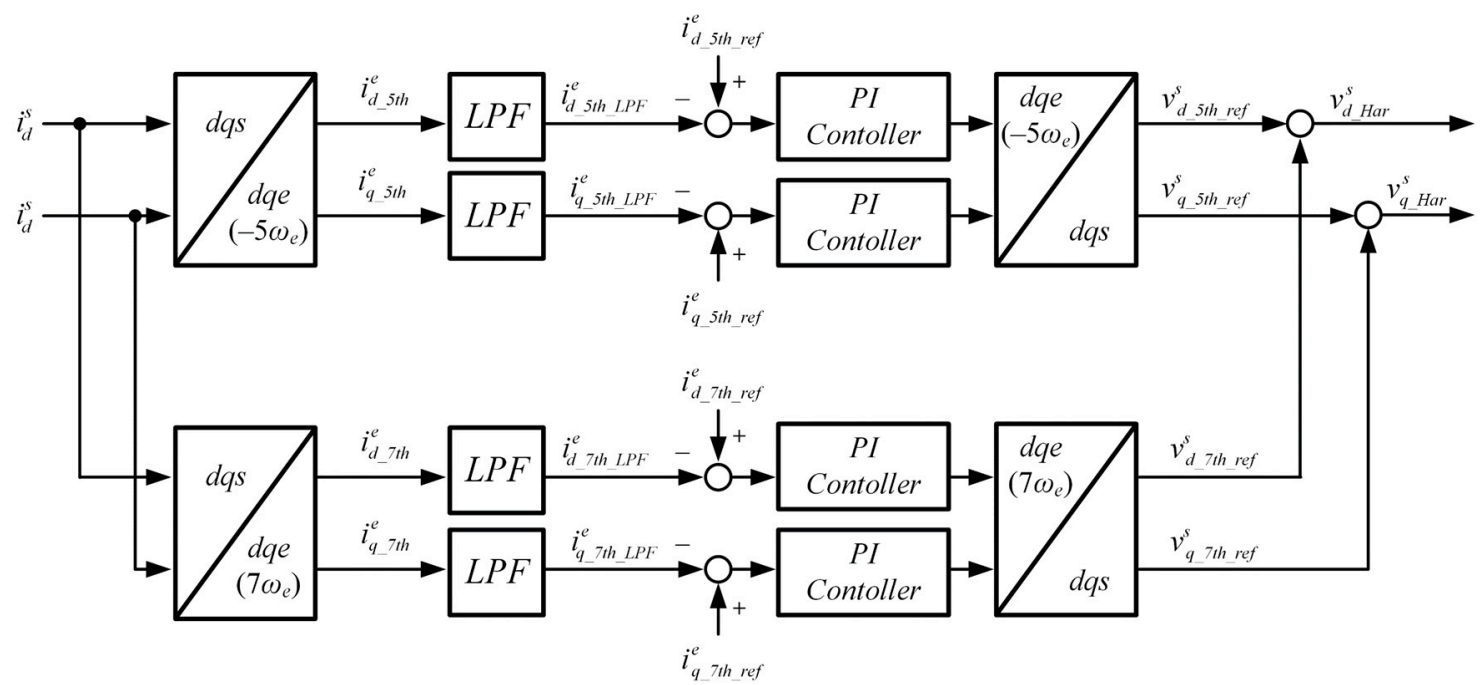

Figure 2. Block diagram of conventional harmonic compensation method. LPF: low pass filter.

The equation for the LPF is expressed as follows:

$$
f_{L P F}(s)=\frac{\omega_{c L}}{s+\omega_{c L}}
$$

where $\omega_{c L}$ is the cutoff frequency for the LPF. In this study, the cutoff frequency for the LPF was set as $6.28 \mathrm{rad} / \mathrm{sec}$. The characteristics of this filter are depicted using a bode plot in Figure 3. The LPF passes input signals in the range of $0 \mathrm{~Hz}$ to the cutoff frequency while filtering all other frequency components. The output values of the LPF are compared to each reference value, then used as inputs for the PI controller for harmonic reduction. Finally, the outputs of each PI controller are re-transformed from a synchronous reference frame to a stationary reference frame. Finally, all harmonic compensation voltages are added to the outputs of the fundamental current controller, as shown in Figure 1.

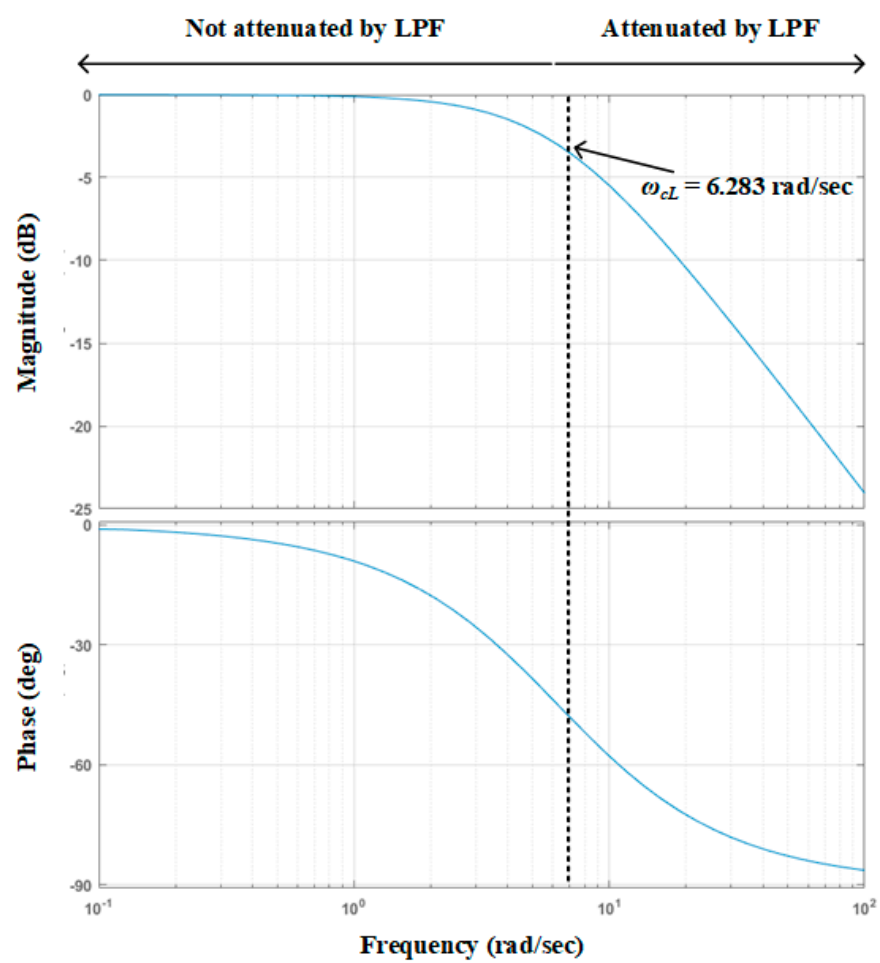

Figure 3. Bode plot of the LPF for the harmonic compensation method $\left(\omega_{c L}=6.283 \mathrm{rad} / \mathrm{sec}\right)$. 
In the conventional harmonic compensation method, the additional calculations for harmonic current reduction require only four additional steps compared to the general current control method using a PI controller. Therefore, the conventional method is advantageous in terms of simplicity. However, despite employing an LPF, the conventional method has limitations in terms of indexing the harmonic signal ratio (HSR) based on the infinitesimal magnitudes of harmonic currents compared to fundamental components. In this paper, the HSR for each harmonic current controller is defined by the following equation:

$$
H S R_{n t h \_h a r}=\left|\frac{i_{n t h \_h a r}}{i_{n t h \_h a r \_L P F}}\right|
$$

where $i_{n t h \_ \text {har }}$ is the magnitude of the nth order harmonic current, and $i_{\text {nth_har_LPF }}$ can be obtained after an input passes through the LPF in a synchronous reference frame. The HSR ranges from zero to one and represents the accuracy of extracting a specific harmonic current. The value of the HSR reaches unity when the extracted signal is the same as the specific harmonic component.

Figure 4 presents a three-phase output current and the corresponding fast frequency transform (FFT) analysis results for fundamental current control under a distorted grid voltage. In this study, the reference current for the fundamental current controller was set to $200 \mathrm{~A}$. Under these conditions, the average values of the fifth and seventh harmonic components in the output current are $7.44 \mathrm{~A}$ and 6.40 A, respectively. Detailed characteristics of the harmonic currents are listed in Table 2.
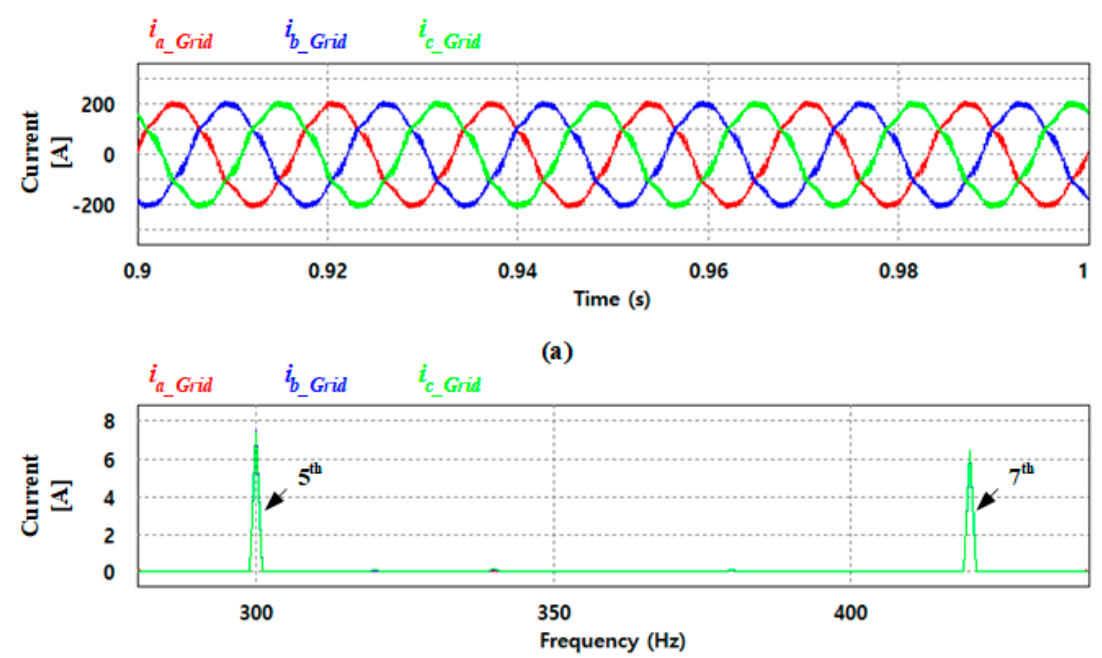

(b)

Figure 4. Waveforms of fundamental current control with a distorted grid voltage: (a) output current, and (b) FFT (fast frequency transform) analysis results.

Table 2. FFT analysis results under the distorted grid condition.

\begin{tabular}{ccc}
\hline Phase & Fifth Harmonic Current & Seventh Harmonic Current \\
\hline A & $7.43 \mathrm{~A}$ & $6.42 \mathrm{~A}$ \\
B & $7.50 \mathrm{~A}$ & $6.36 \mathrm{~A}$ \\
C & $7.38 \mathrm{~A}$ & $6.42 \mathrm{~A}$ \\
Average & $7.44 \mathrm{~A}$ & $6.40 \mathrm{~A}$ \\
\hline
\end{tabular}

As shown in Figure 5, when the conventional method is employed, the magnitudes of the fifth and seventh extracted harmonic currents, which must be reduced, are $30.17 \mathrm{~A}$ and $27.14 \mathrm{~A}$, respectively. In other words, the HSRs of these harmonic components are 0.24 and 0.23 , respectively. Therefore, the extracted signal still contains additional sub-order harmonic currents. The angles $\left(-5 \omega_{e}, 7 \omega_{e}\right)$ for coordinate transformation are distorted by quantization error based on the limit of sampling time. The sampling time for simulation is approximately $104 \mu \mathrm{s}$. The inaccurate magnitudes of extracted harmonic components make it difficult to design accurate controllers, resulting in steady-state errors. 
Therefore, we propose two different methods to overcome these issues related to the conventional harmonic compensation method.
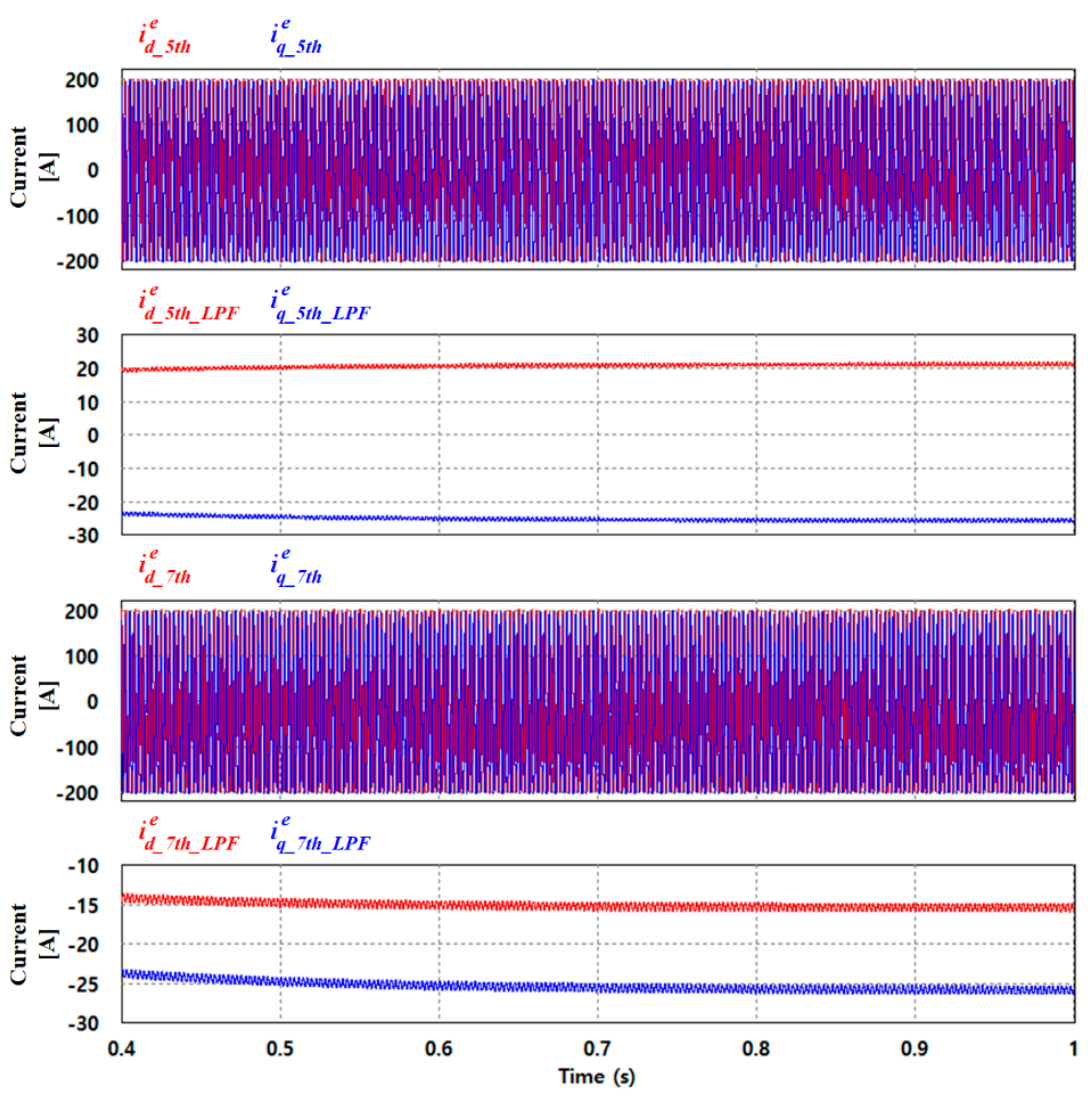

Figure 5. Extracted harmonic currents using the conventional method.

\subsection{Total Harmonic Extractor Method}

Figure 6 presents a block diagram of the THE method. To extract the total harmonic components from each phase current, the THE method utilizes a bandpass filter (BPF) defined by the following equation:

$$
f_{B P F}(s)=\frac{B s}{s^{2}+B s+\omega_{c B}^{2}}
$$

where $B$ and $\omega_{c B}$ are the bandwidth and center frequency of the BPF, respectively.

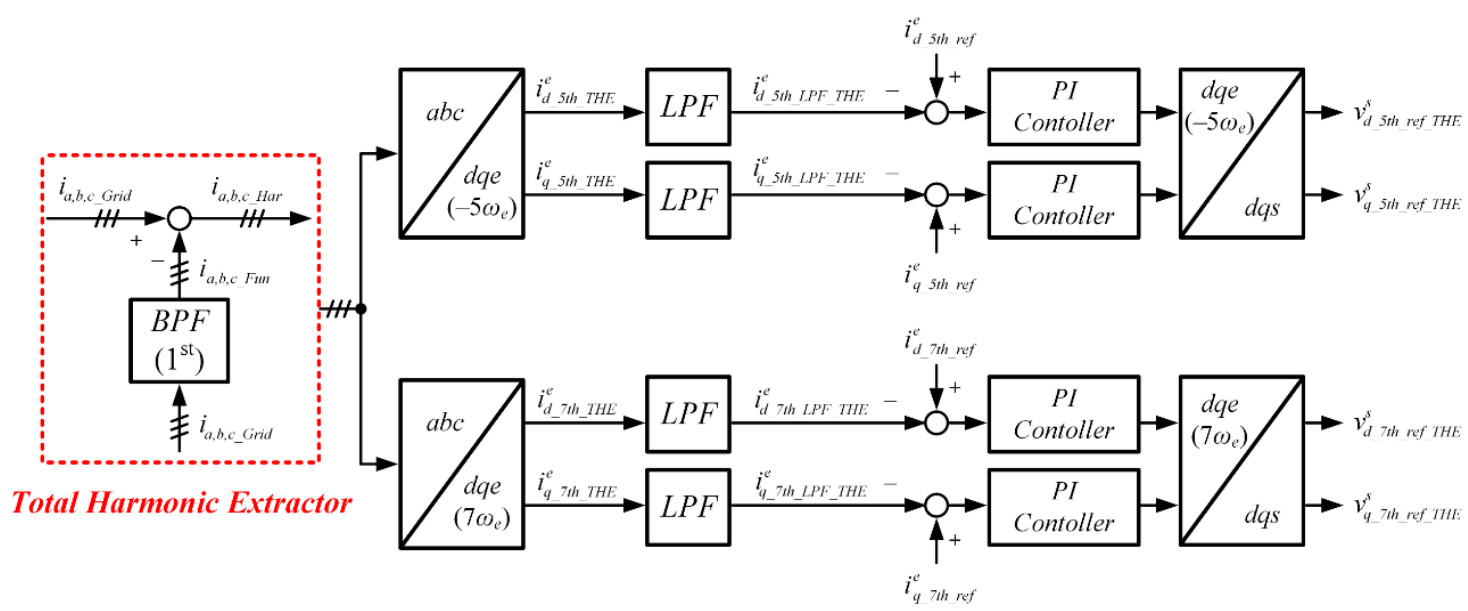

Figure 6. Block diagram of the THE (total harmonic extractor) method. BPF: bandpass filter. 
As shown in Figure 7, the characteristics of the proposed THE method depend on the constant of the BPF.

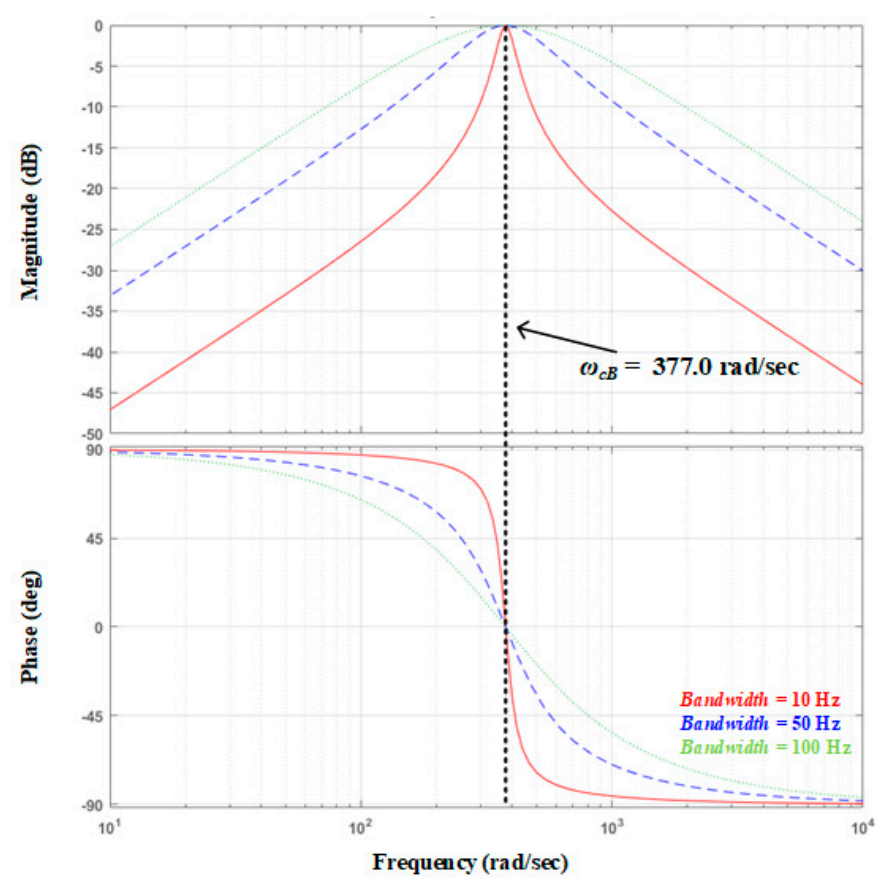

Figure 7. Bode plot of the BPF according to bandwidth in the THE method.

Therefore, optimal selection of this constant is required. In the THE method, the center frequency of the BPF is set to $377.0 \mathrm{rad} / \mathrm{sec}$ to extract only the fundamental frequency component from each phase current. The extracted fundamental currents from each phase are compared to the total current component to extract only the total harmonic current, as follows:

$$
i_{a, b, c_{-} \text {Har }}=i_{a, b, c_{-} \text {grid }}-i_{a, b, c_{-} \text {Fun }}
$$

The total harmonic current from each phase is transformed from the $a b c$ coordinate frame into the $d q$ synchronous coordinate frame, then passed into the first LPF used in the conventional method. Finally, the filtered value is used as an input for the PI controller for harmonic reduction after it is compared to the reference value, which is zero.

The THE method is used to overcome the limitation of the conventional harmonic current compensation method in terms of the HSR. Figure 8 presents the magnitude of each harmonic component extracted in the $d q$ synchronous reference frame by the THE method. The magnitudes of the fifth and seventh harmonic currents are 15.49 A and 11.10 A, respectively, resulting in HSR improvements of 0.48 and 0.57 , respectively. When using the THE method, the performance of the harmonic current controller is improved because the HSR of each order of harmonic current is increased compared to the corresponding values in the conventional method. 


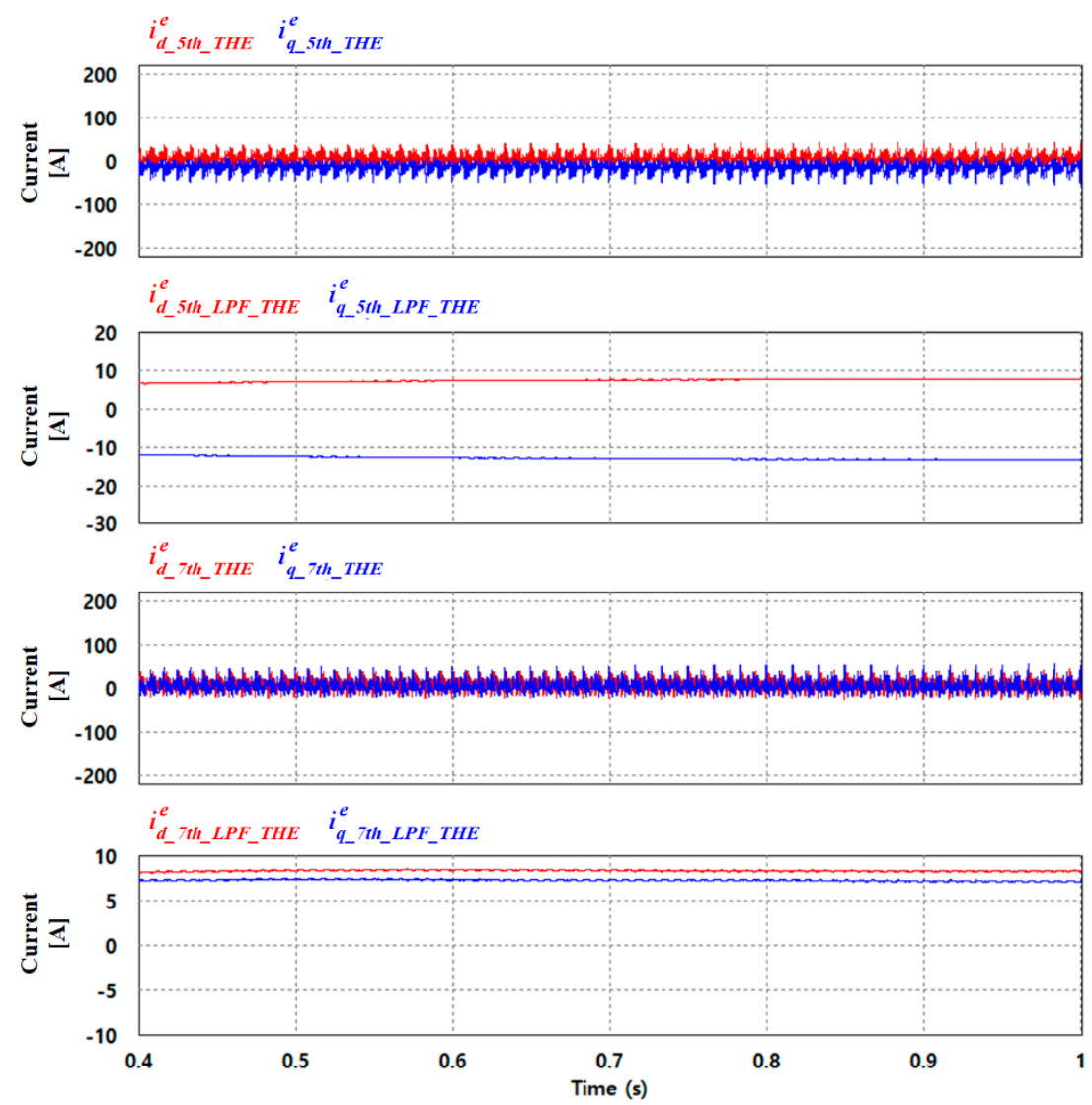

Figure 8. Harmonic currents extracted using the THE method.

\subsection{Selective Harmonic Extractor Method}

Figure 9 presents a block diagram of the SHE method. Compared to the THE method, the SHE method requires a different number of steps to extract the harmonic currents to be reduced from each phase current. In this method, the SHE passes only the harmonic components to be compensated, meaning the BPF is only used to extract the fifth and seventh harmonic currents. Therefore, the center frequency of each filter is focused on each harmonic current, meaning the center frequencies of the $\mathrm{BPF}$ are set to $1885.0 \mathrm{rad} / \mathrm{sec}$ and $2638.9 \mathrm{rad} / \mathrm{sec}$. As shown in Figure 10, only the selected frequency components are passed by the filter based on the characteristics of the BPF. The other components are attenuated based on the bandwidth of the extractor. The extracted harmonic components of each order originating from each phase grid current are transformed into DC values in the synchronous reference frame, which is synchronized to the frequencies of the fifth and seventh harmonic currents. The other AC or noise components are attenuated by the LPF used in the conventional and THE method. Finally, reference voltages are generated when the error between the output of the LPF and the reference current, which is zero, is used as the input for the PI controller. 


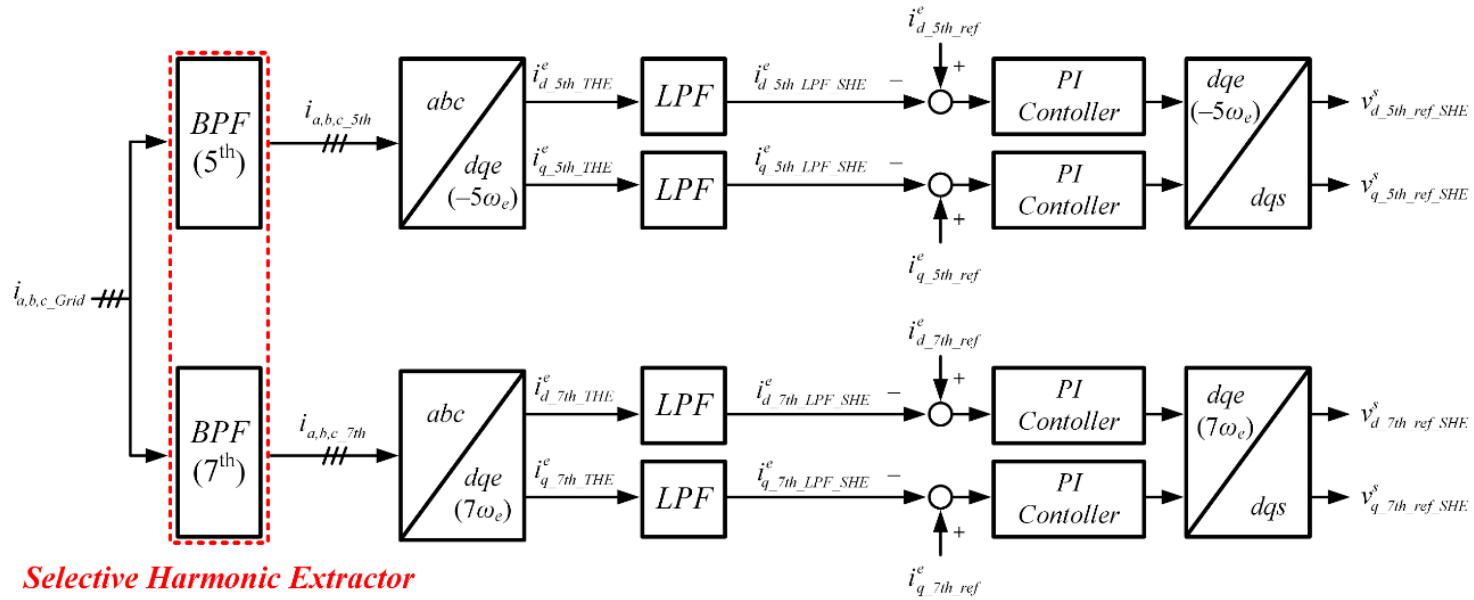

Figure 9. Block diagram of the SHE (selected harmonic extractor) method.

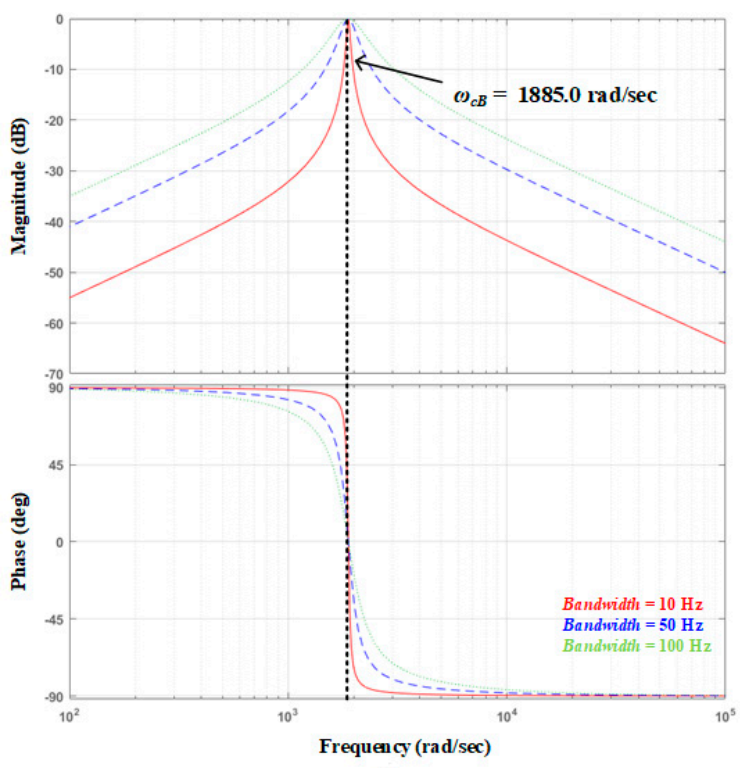

(a)

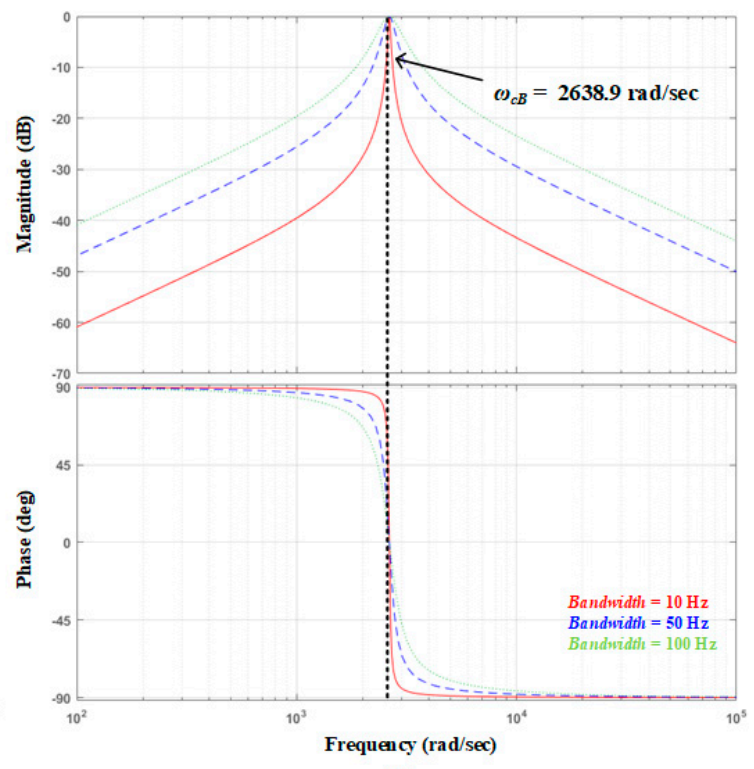

(b)

Figure 10. Bode plot of the BPF according to bandwidth in the SHE method: $(\mathbf{a})$ center frequency $\omega_{c B}=$ $1885.0 \mathrm{rad} / \mathrm{sec},(\mathbf{b})$ center frequency $\omega_{C B}=2638.9 \mathrm{rad} / \mathrm{sec}$.

In terms of HSR, the SHE method is competitive with the other two methods. As shown in Figure 11, the SHE and LPF filter each harmonic component. In this case, the magnitudes of the fifth and seventh extracted harmonic currents are 7.59 A and 7.75 A, respectively, leading to HSR improvements of 0.98 and 0.83 , respectively. When using the SHE method, the performance of the harmonic current controller is improved and the estimation of the gain value for each PI controller is simplified because the HSR of each order harmonic current is increased compared to the corresponding values in the conventional method. A detailed summary of the HSRs for each harmonic compensator is provided in Table 3. 

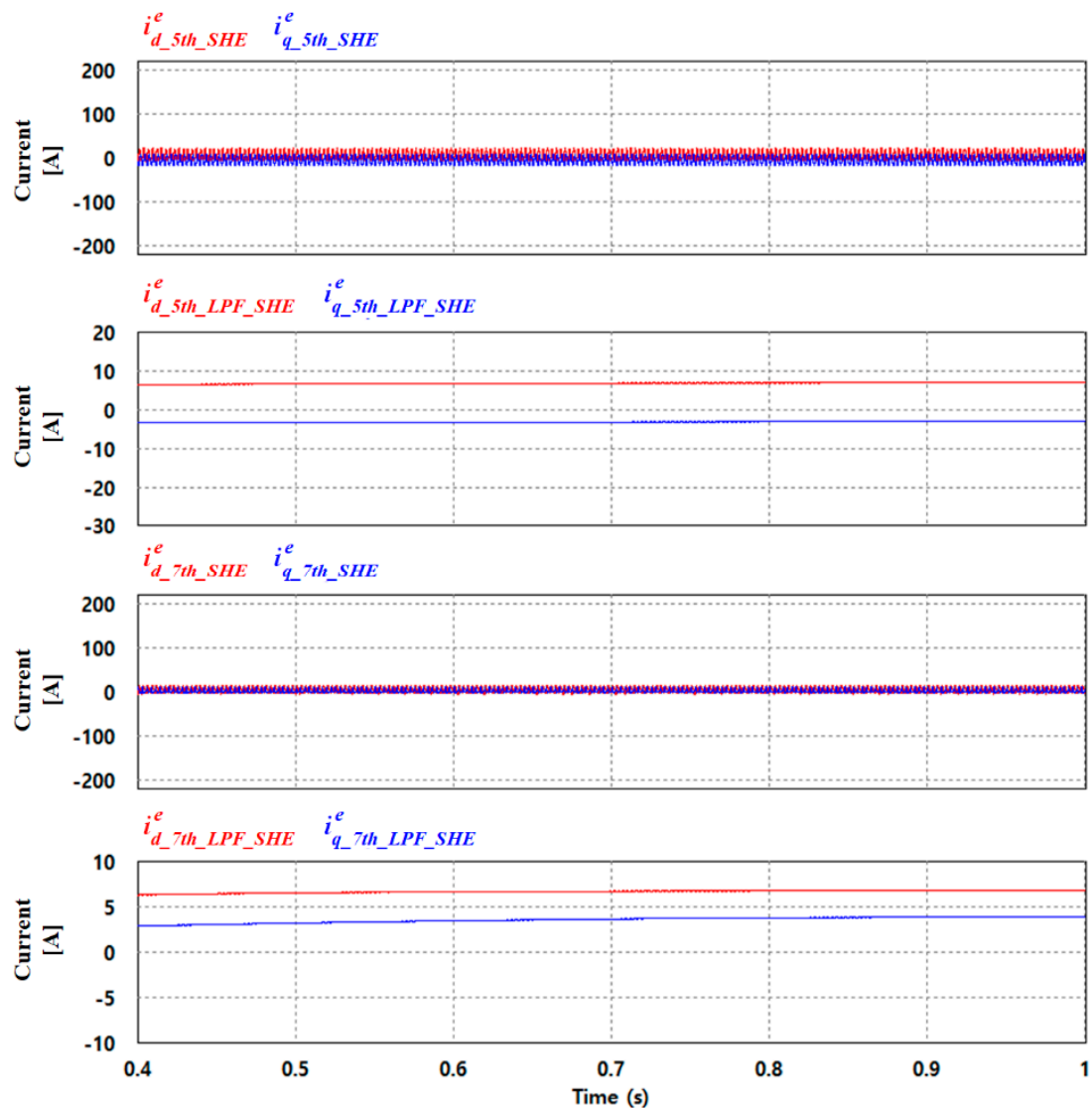

Figure 11. Harmonic currents extracted using the SHE method.

Table 3. Harmonic signal ratio of each harmonic compensator.

\begin{tabular}{ccc}
\hline Categories & Fifth Harmonic Current & Seventh Harmonic Current \\
\hline Conventional method & 0.24 & 0.23 \\
THE method & 0.48 & 0.57 \\
SHE method & 0.98 & 0.83 \\
\hline
\end{tabular}

\section{Simulation Results}

To evaluate the validity of the proposed harmonic compensation methods, simulations were conducted for each algorithm. The system circuit configuration and parameters are shown in Figure 12 and Table 4.

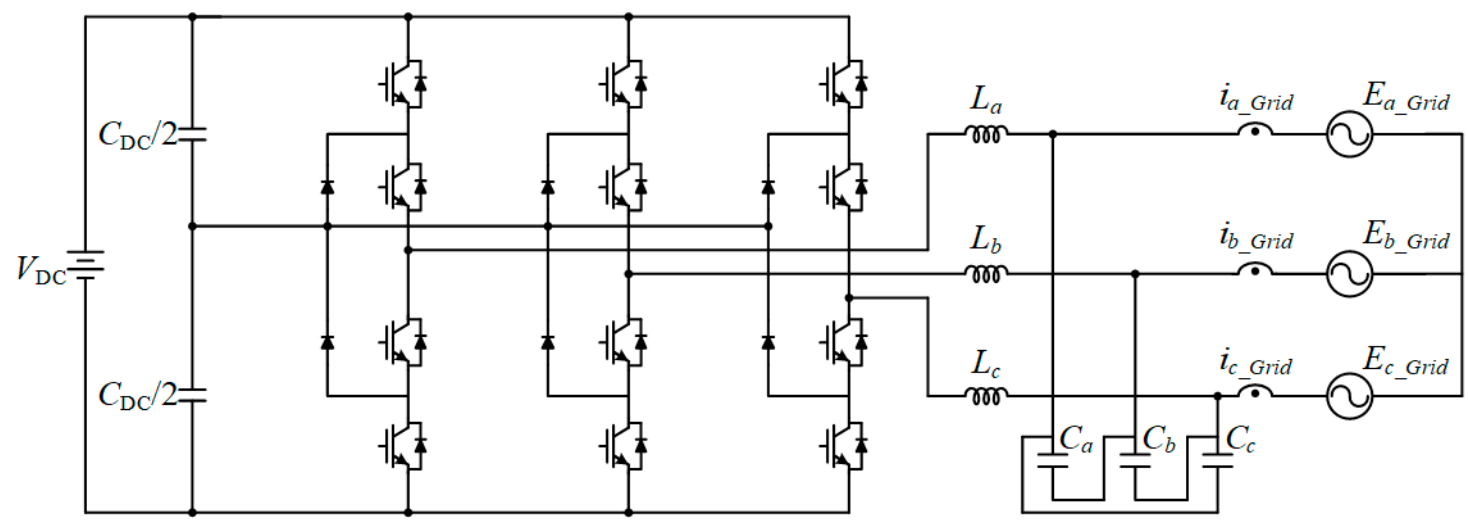

Figure 12. Simulation circuit configuration for the harmonic compensation method (three-level NPC inverter). NPC: neutral point clamped. 
Table 4. Simulation parameters.

\begin{tabular}{ccc}
\hline Parameters & Values & Units \\
\hline Grid voltage $\left(E_{a, b, c}\right.$ Grid $)$ & 220 & $\mathrm{~V}_{\mathrm{rms}}$ \\
Grid frequency $\left(f_{\text {Grid }}\right)$ & 60 & $\mathrm{~Hz}$ \\
Filter inductor $\left(L_{a, b, c}\right)$ & 0.29 & $\mathrm{mH}$ \\
Filter capacitor $\left(C_{a, b, c}\right)$ & 91.84 & $\mu \mathrm{H}$ \\
DC-link capacitance $\left(C_{\mathrm{DC}}\right)$ & 3200 & $\mu \mathrm{F}$ \\
DC-link voltage $\left(V_{\mathrm{DC}}\right)$ & 600 & $\mathrm{~V}$ \\
Switching frequency $\left(f_{\text {sw }}\right)$ & 4.8 & $\mathrm{kHz}$ \\
Sampling time $\left(T_{\text {samp }}\right)$ & 208.33 & $\mu \mathrm{s}$ \\
\hline
\end{tabular}

The maximum value and frequency of grid voltage are set as $220 \mathrm{Vrms}$ and $60 \mathrm{~Hz}$ considering the local grid rated voltage and frequency. Also, the switching frequency of the power stack is set as 4.8 $\mathrm{kHz}$ considering the system efficiency and THD. Moreover, for the adequate calculation time needed for fundamental and harmonic current control, the sampling time is chosen as $208.3 \mu \mathrm{s}$.

Figure 13 presents the simulation results when the conventional harmonic compensation method is applied. The conventional harmonic compensation method only utilizes a PI controller in a synchronous reference frame, as shown in Figure 2. Compared to the simulation waveform without a harmonic current controller, the average THD of three-phase output current is improved from $6.66 \%$ to $5.10 \%$ by the conventional method. Additionally, the fifth and seventh harmonic currents are reduced by $3.97 \mathrm{~A}$ and $3.91 \mathrm{~A}$, respectively.
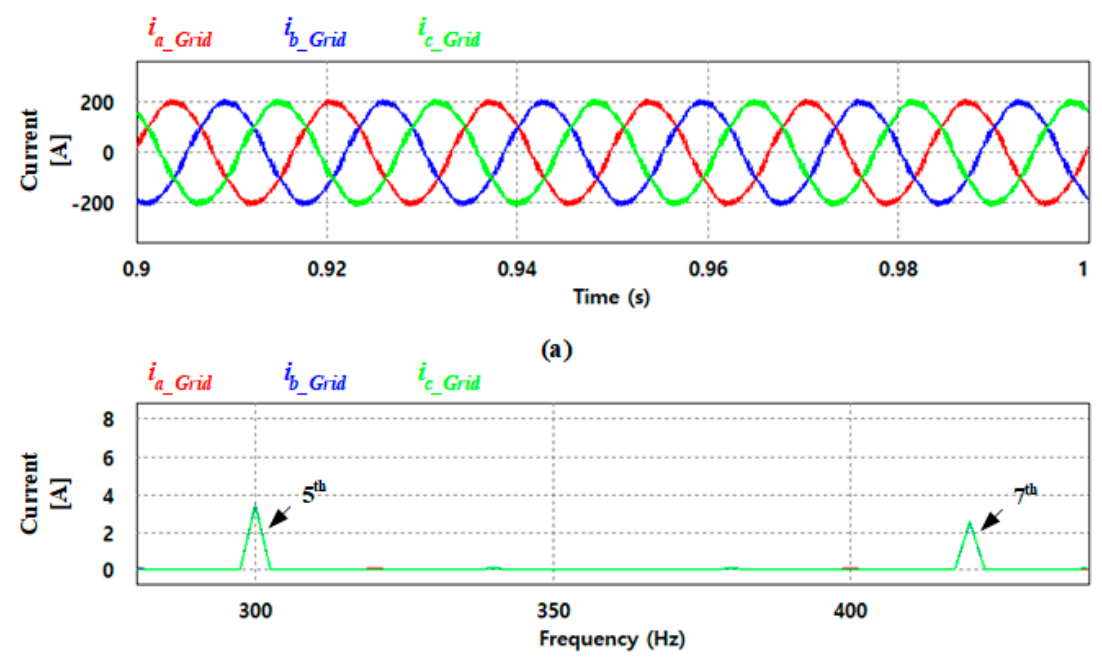

(b)

Figure 13. Simulation waveforms when applying the conventional method: (a) output current, (b)FFT analysis result.

Figure 14 presents the simulation results when the THE method is utilized to reduce low-order harmonic currents. The simulation waveforms represent the results when the total bandwidth of the harmonic extractor is set to $50 \mathrm{~Hz}$. As shown in Figure 14, the THD of the output current is reduced to $4.61 \%$. Additionally, the fifth and seventh harmonic currents are reduced from $7.46 \mathrm{~A}$ and $6.40 \mathrm{~A}$ to $0.24 \mathrm{~A}$ and $0.22 \mathrm{~A}$, respectively. The performance of the THE method can be tuned to some extent by modifying the bandwidth of the extractor because the set bandwidth determines if the sideband components around the center frequency have passed. Performance metrics with different bandwidth values for the BPF are listed in Table 5. One can see that the performance metrics for the THE method are relatively consistent for different bandwidth values based on continuous comparisons between extracted fundamental currents and total current components. 

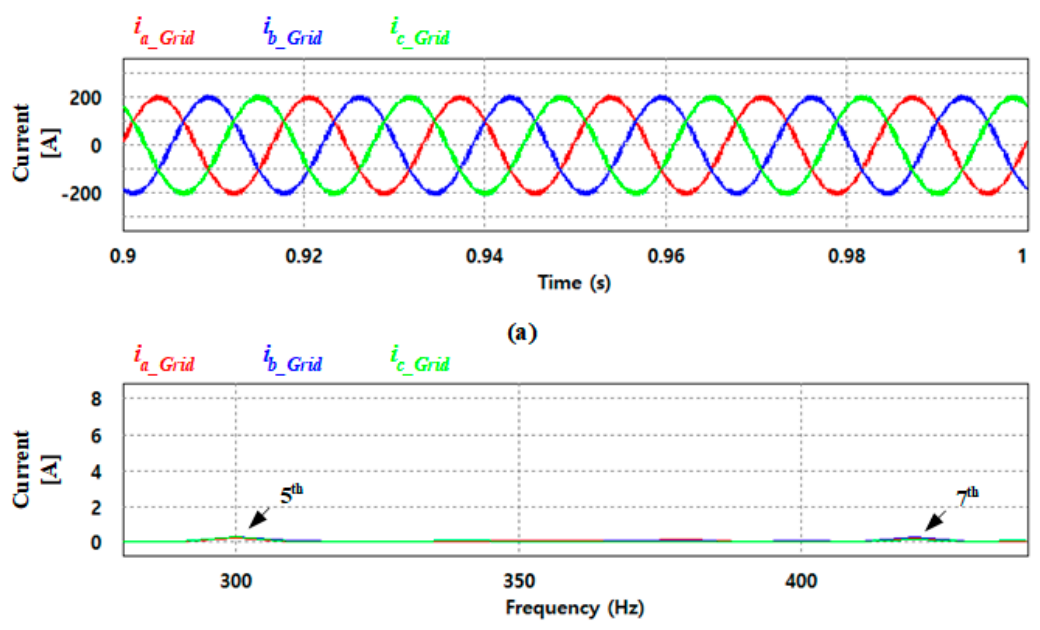

(b)

Figure 14. Simulation waveforms when applying the THE method: (a) output current, (b) FFT analysis result.

Table 5. Performances of the THE method for different bandwidths.

\begin{tabular}{cccc}
\hline Categories & Fifth Harmonic Current & Seventh Harmonic Current & THD \\
\hline Bandwidth $=100 \mathrm{~Hz}$ & $0.28 \mathrm{~A}$ & $0.24 \mathrm{~A}$ & $4.61 \%$ \\
Bandwidth $=50 \mathrm{~Hz}$ & $0.24 \mathrm{~A}$ & $0.22 \mathrm{~A}$ & $4.61 \%$ \\
Bandwidth $=10 \mathrm{~Hz}$ & $0.26 \mathrm{~A}$ & $0.21 \mathrm{~A}$ & $4.61 \%$ \\
\hline
\end{tabular}

Figure 15 presents the simulation results when the SHE method is applied. To extract low-order harmonic components, the bandwidth of the SHE is set to $10 \mathrm{~Hz}$. After applying the SHE method, the THD of the output current is improved to $4.60 \%$. Additionally, one can see that the fifth and seventh harmonic components are virtually eliminated. As shown in Figure 9, the SHE method can eliminate one processing step compared to the THE method, namely the extraction of each order of harmonic current. However, the simulation results reveal that the performance of the SHE method is more heavily dependent on the characteristics of the extractor compared to the THE method. Table 6 lists performance metrics for the SHE method based on bandwidth under consistent controller gain value conditions. When the bandwidth of the extractor is narrowed, the performance of the SHE method is improved.
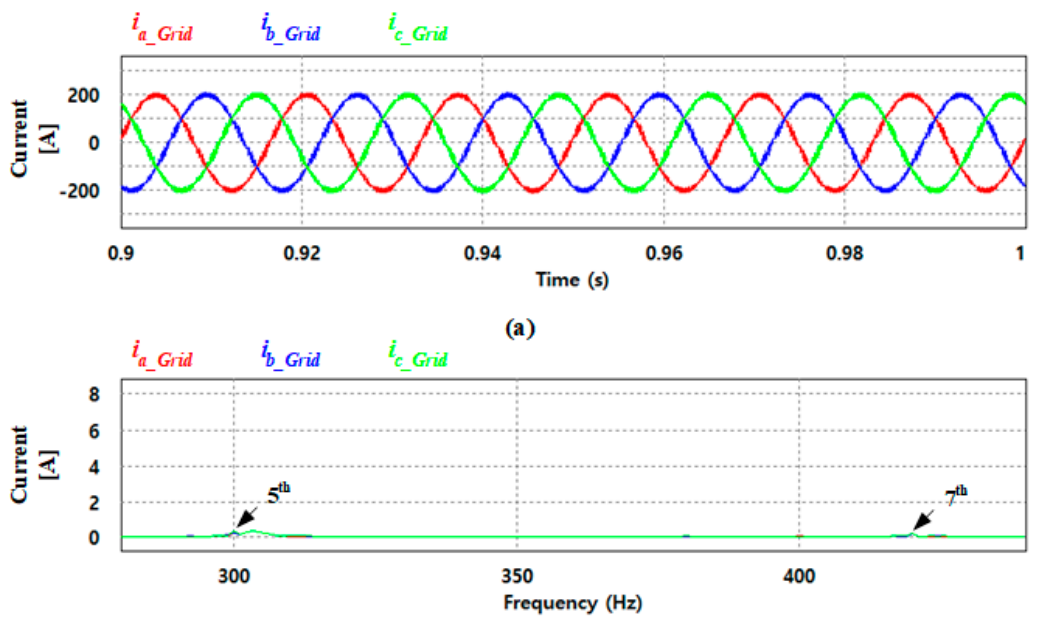

(b)

Figure 15. Simulation waveforms when applying the SHE method: (a) output current, (b) FFT analysis result. 
Table 6. Performances of the SHE method for different the bandwidths.

\begin{tabular}{cccc}
\hline Categories & Fifth Harmonic Current & Seventh Harmonic Current & THD \\
\hline Bandwidth $=100 \mathrm{~Hz}$ & $1.85 \mathrm{~A}$ & $1.27 \mathrm{~A}$ & $4.73 \%$ \\
Bandwidth $=50 \mathrm{~Hz}$ & $0.96 \mathrm{~A}$ & $0.69 \mathrm{~A}$ & $4.64 \%$ \\
Bandwidth $=10 \mathrm{~Hz}$ & $0.23 \mathrm{~A}$ & $0.11 \mathrm{~A}$ & $4.60 \%$ \\
\hline
\end{tabular}

The performances of each harmonic compensation method were compared in terms of the magnitudes of the fifth and seventh harmonic currents, as well as THD. The results are summarized in Table 7. Compared to the conventional method, the proposed methods improve the average THD of three-phase output currents by approximately $0.5 \%$. Additionally, the fifth and seventh harmonic currents are reduced by approximately $3.20 \mathrm{~A}$ and $2.20 \mathrm{~A}$, respectively, when using the proposed methods.

Table 7. Analysis of output current depending on the harmonic compensation method.

\begin{tabular}{|c|c|c|c|c|c|}
\hline Phase & Categories & Controller Off & Conventional Method & THE Method & SHE Method \\
\hline \multirow{3}{*}{$\mathrm{A}$} & $5^{\text {th }}$ & $7.42 \mathrm{~A}$ & $3.39 \mathrm{~A}$ & $0.24 \mathrm{~A}$ & $0.20 \mathrm{~A}$ \\
\hline & $7^{\text {th }}$ & $6.43 \mathrm{~A}$ & $2.47 \mathrm{~A}$ & $0.24 \mathrm{~A}$ & $0.11 \mathrm{~A}$ \\
\hline & THD & $6.66 \%$ & $5.12 \%$ & $4.61 \%$ & $4.60 \%$ \\
\hline \multirow{3}{*}{ B } & $5^{\text {th }}$ & $7.52 \mathrm{~A}$ & $3.52 \mathrm{~A}$ & $0.26 \mathrm{~A}$ & $0.16 \mathrm{~A}$ \\
\hline & $7^{\text {th }}$ & $6.38 \mathrm{~A}$ & $2.45 \mathrm{~A}$ & $0.22 \mathrm{~A}$ & $0.11 \mathrm{~A}$ \\
\hline & THD & $6.74 \%$ & $5.14 \%$ & $4.60 \%$ & $4.60 \%$ \\
\hline \multirow{3}{*}{$\mathrm{C}$} & $5^{\text {th }}$ & $7.43 \mathrm{~A}$ & $3.51 \mathrm{~A}$ & $0.23 \mathrm{~A}$ & $0.34 \mathrm{~A}$ \\
\hline & $7^{\text {th }}$ & $6.40 \mathrm{~A}$ & $2.55 \mathrm{~A}$ & $0.19 \mathrm{~A}$ & $0.11 \mathrm{~A}$ \\
\hline & THD & $6.66 \%$ & $5.13 \%$ & $4.62 \%$ & $4.60 \%$ \\
\hline
\end{tabular}

To verify the performance at the transient state of the proposed harmonic compensation method, simulations are conducted. Figures 16 and 17 shows the simulation results which applied the conventional or proposed method when the magnitude of grid voltage was changed from $311 \mathrm{~V}$ to $250 \mathrm{~V}$ at $0.3 \mathrm{~s}$. When the conventional method is utilized, the settling time of the current waveform is within $4 \mathrm{msec}$. Additionally, the fifth and seventh harmonic currents are reduced up to about $3.2 \mathrm{~A}$ and 4.0 A. If the proposed THE or SHE method are applied, as shown in Figure 17, the settling time of the grid current is almost same as the case using the conventional method. On the other hand, the fifth and seventh harmonic currents are decreased to below 1.5 A. Meanwhile, under the condition of the grid voltage frequency being changed from $60 \mathrm{~Hz}$ to $50 \mathrm{~Hz}$ at $0.3 \mathrm{~s}$, the transient characteristics depending on the sort of harmonic compensation method are shown in Figures 18 and 19. Regardless of the difference in the harmonic compensation method, the current controllers show a stable operation even though the grid frequency changes suddenly. The proposed THE or SHE method has almost the same dynamic response against external disturbances such as grid voltage amplitude or frequency variation. 

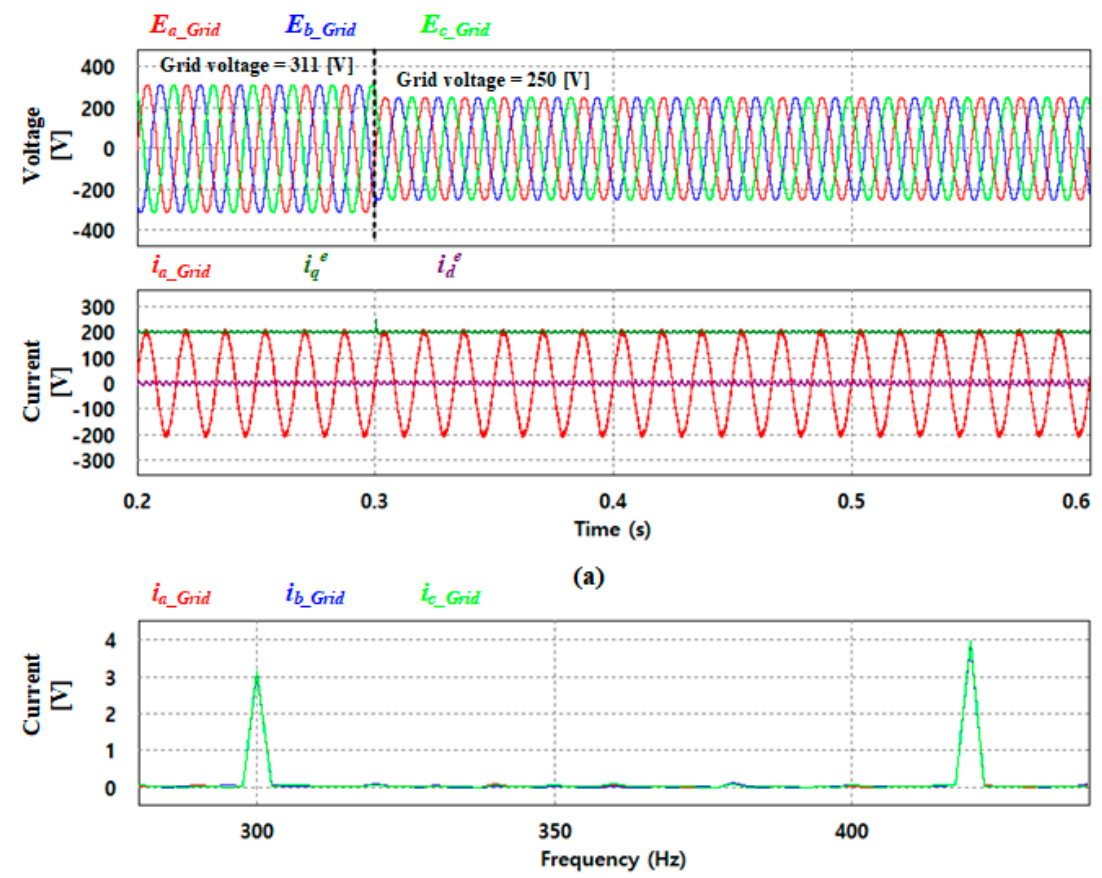

(b)

Figure 16. Conventional harmonic compensation method (grid voltage: $311 \mathrm{~V} \rightarrow 250 \mathrm{~V}$ ): (a) three-phase grid voltage, a-phase current, and d-q axis current; (b) FFT analysis result of three-phase current.
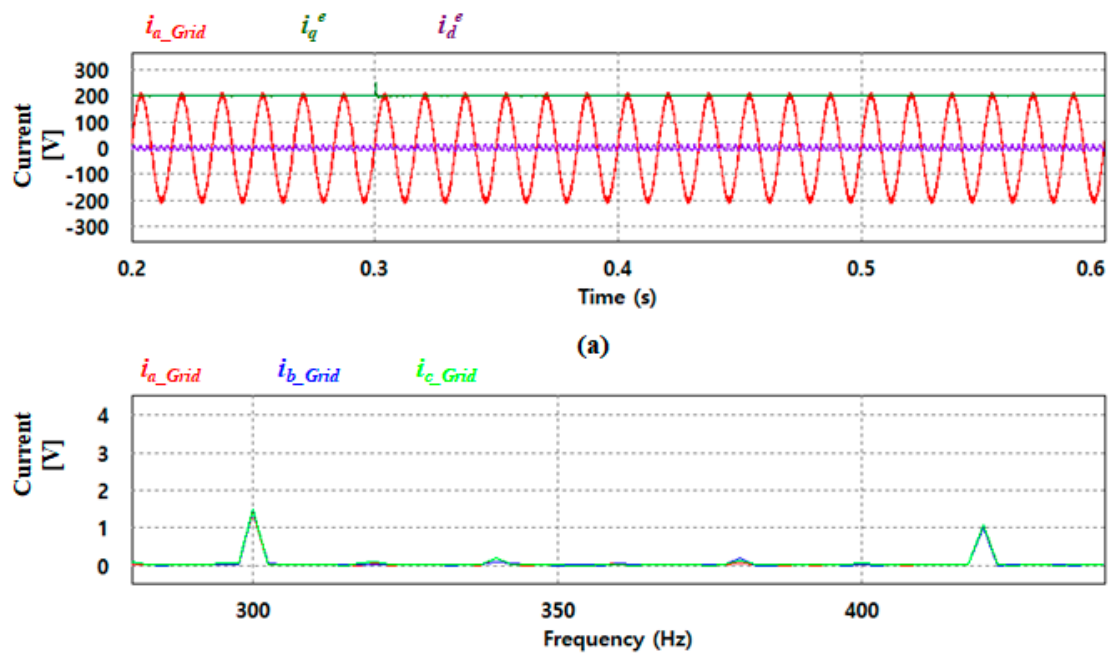

(b)

Figure 17. Proposed harmonic compensation method (grid voltage: $311 \mathrm{~V} \rightarrow 250 \mathrm{~V}$ ): (a) three-phase grid voltage, a-phase current, and d-q axis current; (b) FFT analysis result of three-phase current. 

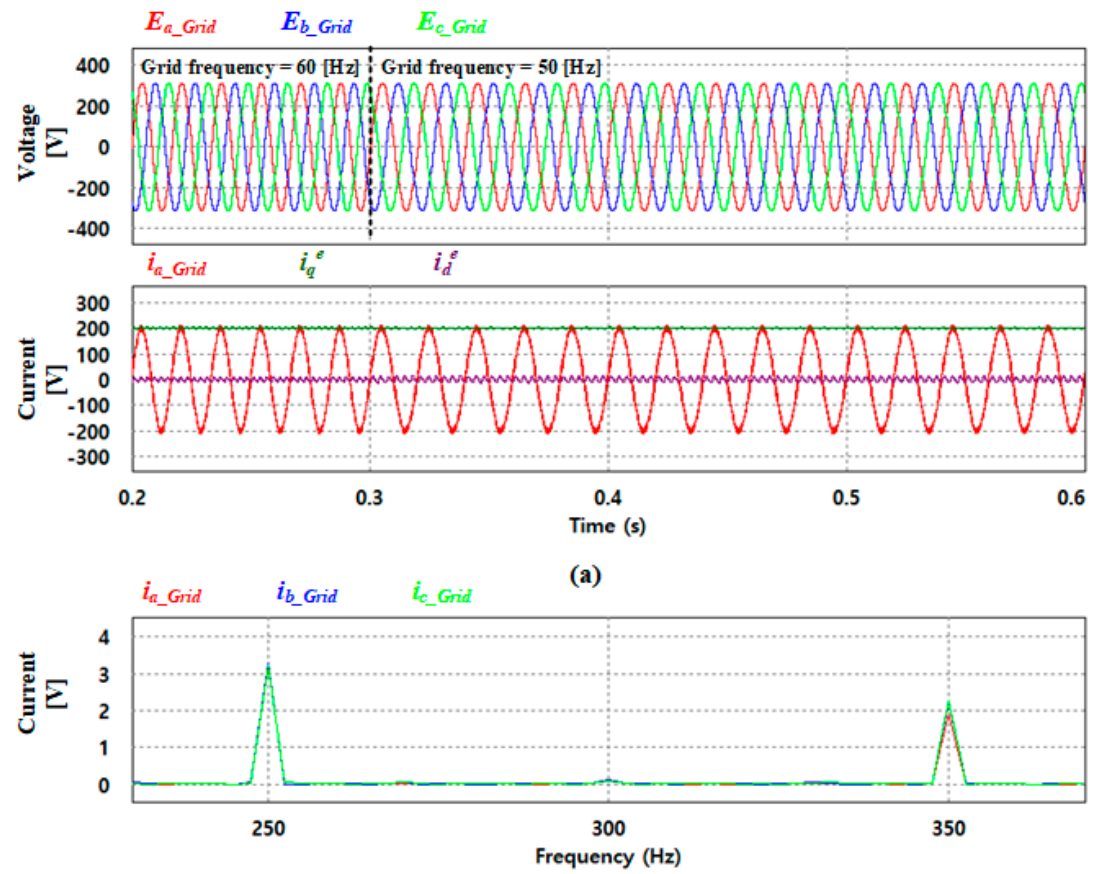

(b)

Figure 18. Conventional harmonic compensation method (grid frequency: $60 \mathrm{~Hz} \rightarrow 50 \mathrm{~Hz}$ ): (a) three-phase grid voltage, a-phase current, and d-q axis current; (b) FFT analysis result of three-phase current.
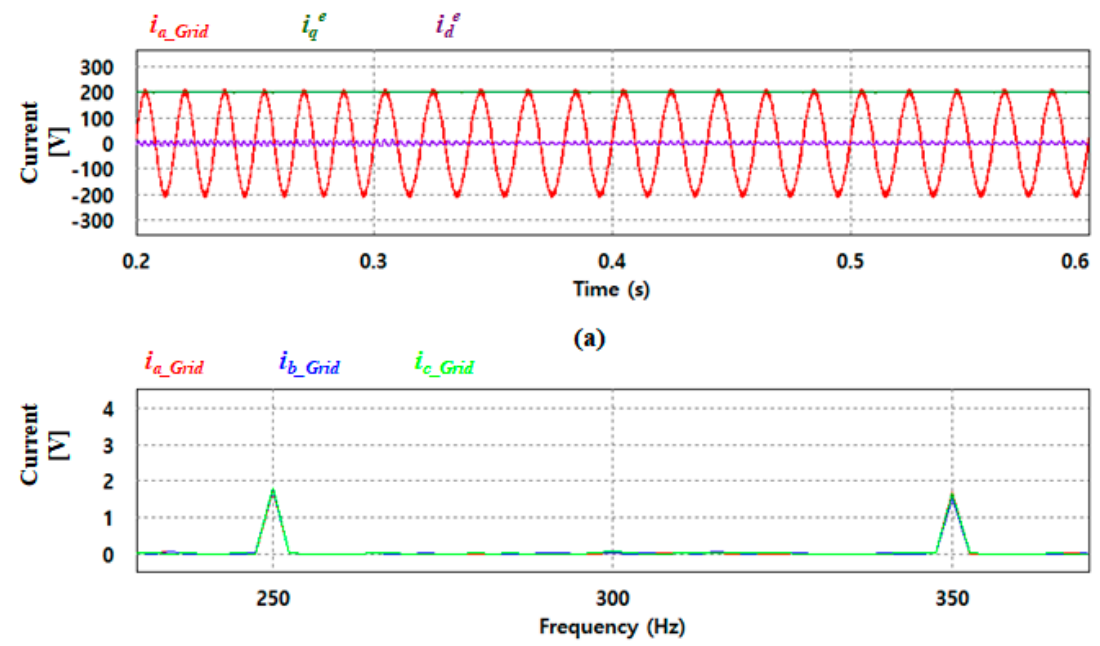

(b)

Figure 19. Proposed harmonic compensation method (grid frequency: $60 \mathrm{~Hz} \rightarrow 50 \mathrm{~Hz}$ ): (a) three-phase grid voltage, a-phase current, and d-q axis current; (b) FFT analysis result of three-phase current.

\section{Experimental Results}

To verify the performance of the proposed harmonic current controller, a three-phase $100 \mathrm{~kW}$ prototype of a power conditioning system (PCS) was constructed, as shown in Figure 20. The PCS consists of the following equipment: a control board, power stack, and filter. The control board was built based on a TMS320F28335 controller, and the power stack used in the hardware setup is a SEMIX305MLI12E4 model by SEMIKRON. The filter was added to cut off high-frequency harmonic currents with impedance parameters of $0.28 \mathrm{mH}$ and $91.84 \mu \mathrm{F}$. As indicated in Table 4, most of the experimental parameters were the same as those in the simulations, except that the magnitudes of each order of harmonic voltage and grid impedance can fluctuate in real time. 

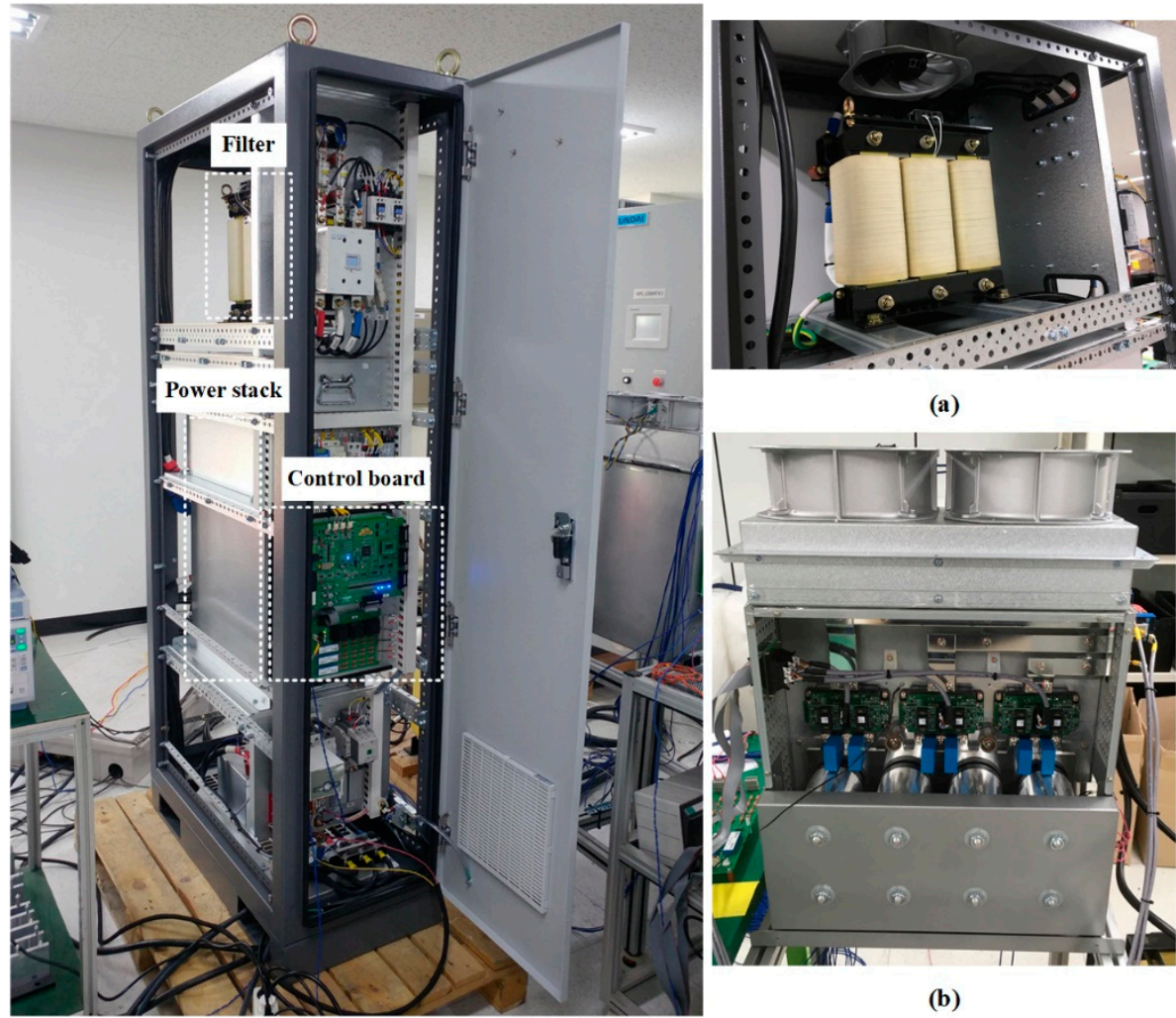

(a)

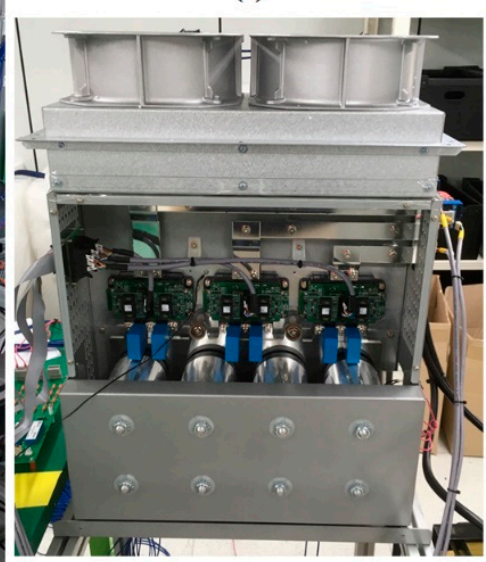

(b)

Figure 20. Experimental setup for the proposed harmonic compensation method: (a) filter of PCS (power control system), (b) PCS power stack.

Figure 21 presents the experimental results for an a-phase current when no harmonic current compensation method is applied. One can see that the magnitude of the fundamental frequency current is controlled to $200 \mathrm{~A}$ and the fifth and seventh harmonic currents are approximately $12.4 \mathrm{~A}$ and $4.8 \mathrm{~A}$, respectively. As shown in the waveform of the a-phase current, the quality of the output currents is deteriorated by low-order harmonic currents. In this case, the THD of the output current is approximately $5.8 \%$.
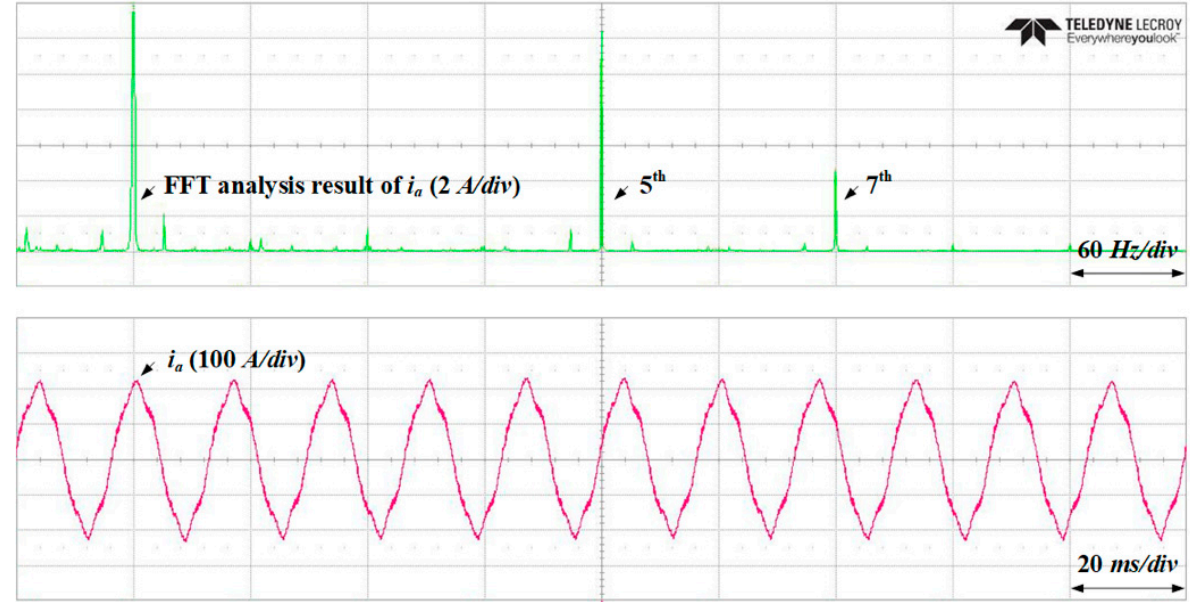

Figure 21. Experimental results when no harmonic compensation method is applied.

Figure 22 presents the experimental results when the conventional harmonic compensation method is applied. The gain values for each harmonic controller were tuned individually. The fifth and seventh harmonic currents are reduced to $9.0 \mathrm{~A}$ and $2.4 \mathrm{~A}$, respectively, and the THD of the 
a-phase current is improved by approximately $2.7 \%$. The quality of the output currents is improved, but significant low-order harmonic currents remain.
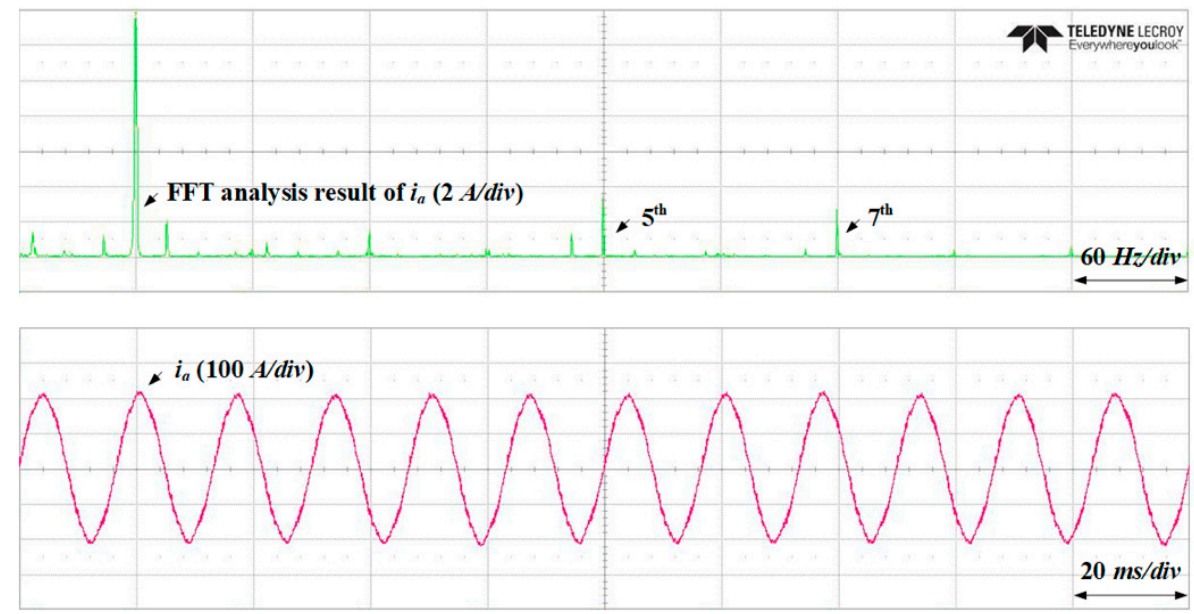

Figure 22. Experimental results when a harmonic compensation method is applied: conventional method.

Figure 23 presents the experimental results when the THE method is utilized to reduce low-order harmonic currents. The THE method decreases the fifth and seventh harmonic currents from $12.4 \mathrm{~A}$ to $1.7 \mathrm{~A}$ and $4.8 \mathrm{~A}$ to $0.9 \mathrm{~A}$, respectively. Additionally, the THD of the output current is improved by $3.4 \%$ compared to the case when no harmonic compensation method is applied.

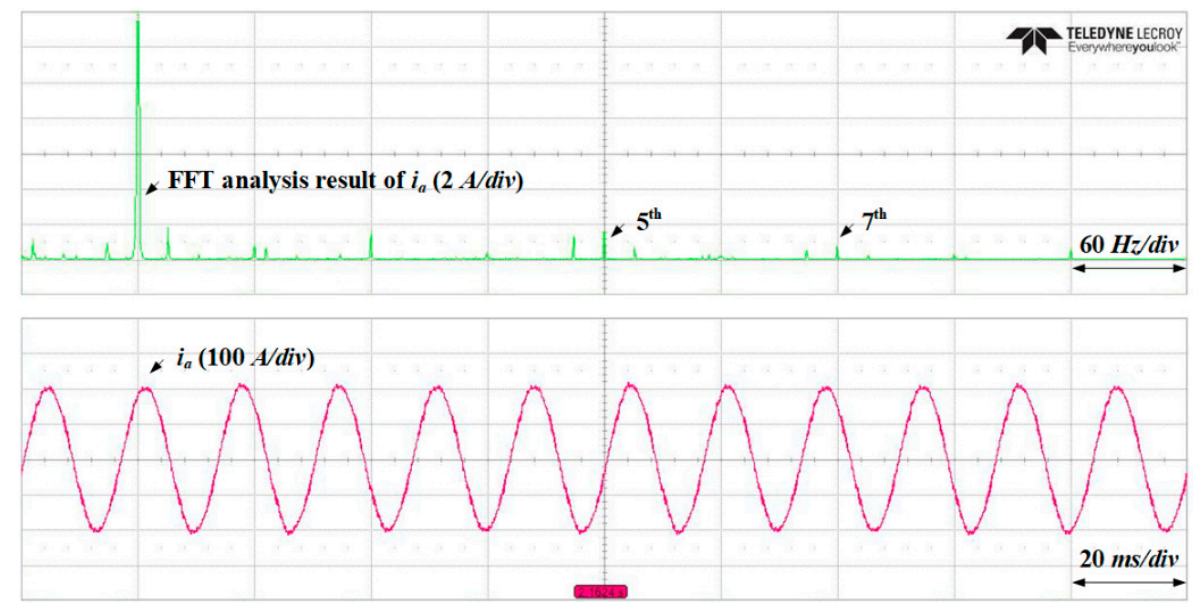

Figure 23. Experimental results when a harmonic compensation method is applied: THE method.

The experimental results for the SHE method are presented in Figure 24. The fifth and seventh harmonic currents are reduced to $1.5 \mathrm{~A}$ and $0.8 \mathrm{~A}$, respectively, and the THD of the output current is reduced by $2.1 \%$. Similar to the simulation results, the experimental results demonstrate that the two proposed methods improved the quality of output currents compared to the conventional harmonic compensation method. In particular, the SHE method yields excellent results in terms of reducing the target harmonic components. The performances of each harmonic compensation method are summarized in Figure 25. 


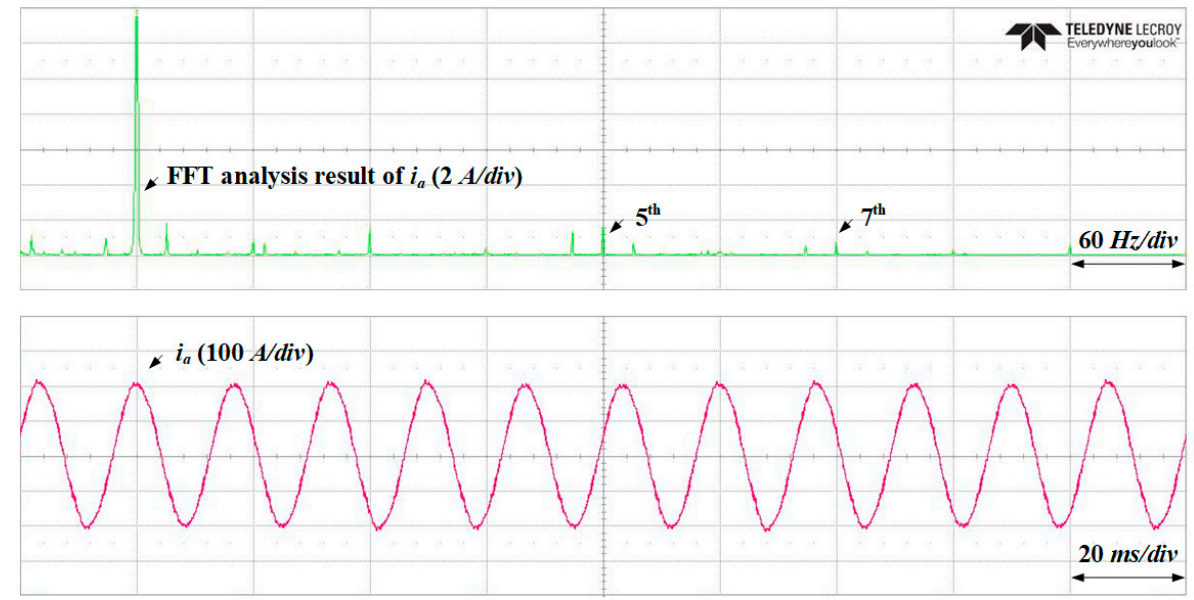

Figure 24. Experimental results when a harmonic compensation method is applied: SHE method.

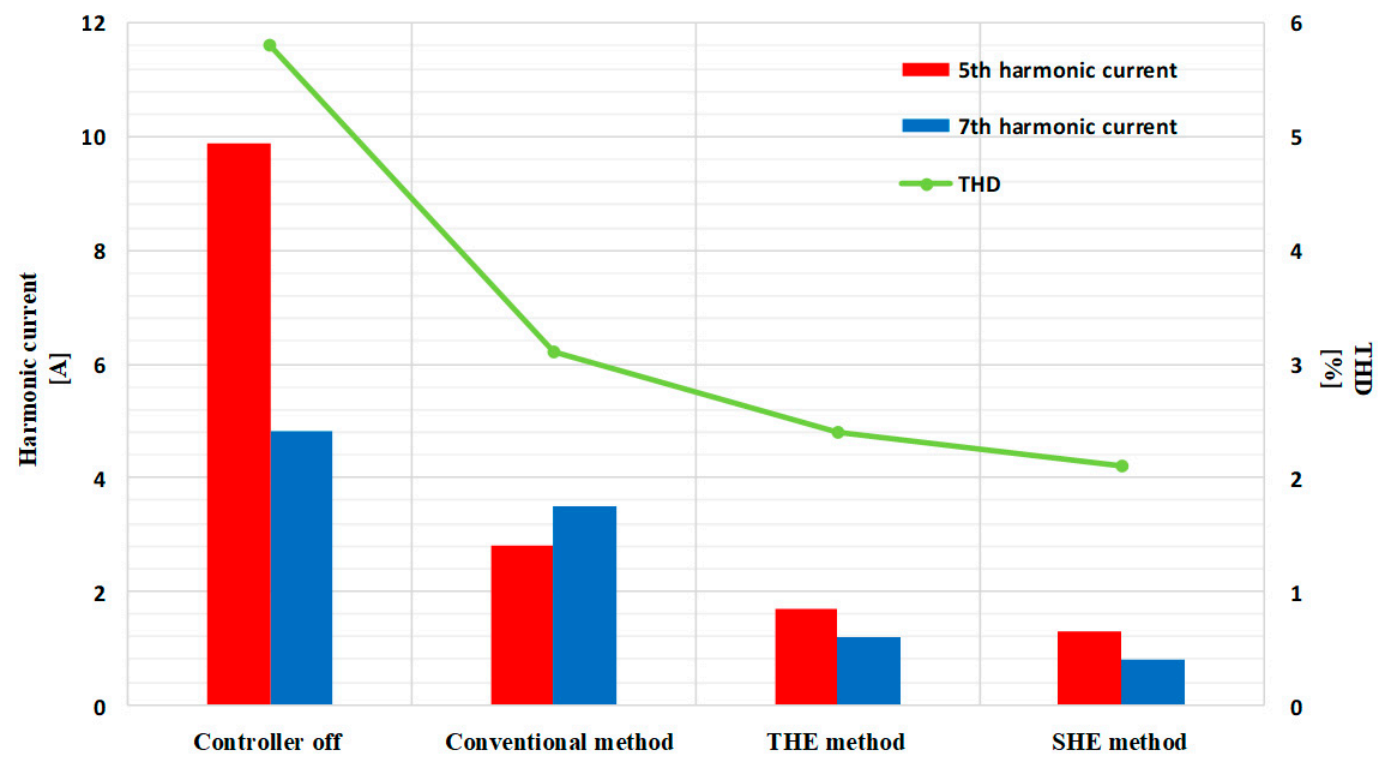

Figure 25. Experimental results analysis of output currents based on harmonic compensation method.

\section{Conclusions}

This paper introduced an improved current control strategy for grid-connected inverter systems operating under distorted grid voltage conditions. The proposed methods only require a few additional steps based on including an additional BPF to existing fundamental current control loops to improve the THD of output currents. Compared to conventional current compensation methods, the proposed methods can effectively reduce target harmonic currents without any additional hardware or complicated control methods. Simulation results based on the PSIM software and experimental results based on a $100 \mathrm{~kW}$ inverter system demonstrated the validity of the proposed harmonic current reduction methods. As shown in the results of the test, the proposed harmonic compensator has not only good static performance but also good dynamic performance under a distorted grid voltage. Considering various grid conditions and increasing distributed generation systems, the specific harmonic order for reduction can be changed. Therefore, further study is necessary to find a better way to achieve harmonic reduction when multiple inverter modules are installed at the point of common coupling.

Author Contributions: J.-Y.Y. provided guidance and supervision. K-B.L. managed this project. H.-S.K. conducted the simulation and experiment. S.C. conceived the idea of this paper and revised the manuscript. 
Funding: This work was supported by "Human Resources Program in Energy Technology" and "Demonstration and Development of ESS Solution Connected with Renewable Energy against with the weather condition of Middle East Region" of the Korea Institute of Energy Technology Evaluation and Planning (KETEP), granted financial resource from the Ministry of Trade, Industry \& Energy, Republic of Korea. (No. 20194030202370, 20182410105160).

Conflicts of Interest: The authors declare no conflict of interest.

\section{References}

1. Strasser, T.; Andren, F.; Kathan, J.; Cecati, C.; Bucella, C. A review of architectures and concepts for intelligence in future electric energy systems. IEEE Trans. Ind. Electron. 2014, 62, 2424-2438. [CrossRef]

2. Chiacchio, F.; Famoso, F.; D’Urso, D.; Cedola, L. Performance and economic assessment of a grid-connected photovoltaic power plant with a storage system: A comparison between the north and the south of Italy. Energies 2019, 12, 2356. [CrossRef]

3. Liu, S.; Wang, X.; Liu, P.X. A stochastic stability enhancement method of grid-connected distributed energy storage systems. IEEE Trans. Smart Grid. 2017, 8, 2062-2070. [CrossRef]

4. Xu, Y.; Li, Z.; Zhao, J.; Zhang, J. Distributed robust control strategy of grid-connected inverters for energy storage systems' state-of-charge balancing. IEEE Trans. Smart Grid. 2017, 9, 5907-5917. [CrossRef]

5. Akter, M.P.; Mekhilef, S.; Tan, N.M.L.T.; Akagi, H. Modified model predictive control of a bidirectional AC-DC converter based on Lyapunov function for energy storage systems. IEEE Trans. Ind. Electron. 2016, 63, 704-715. [CrossRef]

6. Lee, J.-H.; Lee, J.-S.; Moon, H.-C.; Lee, K.-B. An improved finite-set model predictive control based on discrete space vector modulation for grid-connected three-level voltage source inverter. IEEE J. Emerging Sel. Top. Power Electron. 2018, 6, 1744-1760. [CrossRef]

7. Moon, H.C.; Lee, J.-S.; Lee, K.-B. A robust deadbeat finite set model predictive current control based on discrete space vector modulation for grid-connected voltage source inverter. IEEE Trans. Energ. Conver. 2018, 33, 1719-1728. [CrossRef]

8. Zhong, Q.-C. Harmonic droop controller to reduce the voltage harmonics of inverters. IEEE Trans. Ind. Electron. 2013, 60, 936-945. [CrossRef]

9. Liu, H.; Zhou, J.; Wang, W.; Xu, D. Droop control scheme of a three-phase inverter for grid voltage unbalance compensation. J. Power Electron. 2018, 1, 270-279.

10. Tao, Y.; Tang, W. Virtual flux and positive-sequence power based control of grid-interfaced converters against unbalanced and distorted grid conditions. J. Electr. Eng. Technol. 2018, 3, 1265-1274.

11. IEEE Std.1547.2-2008. IEEE Application Guide for IEEE Std 1547, IEEE Standard for Interconnecting Distributed Resources with Electric Power Systems. 2008. [CrossRef]

12. Blaabjerg, F.; Teodorescu, R.; Liserre, M.; Timbus, A.V. Overview of control and grid synchronization for distributed power generation systems. IEEE Trans. Ind. Electron. 2006, 53, 1398-1409. [CrossRef]

13. Palanisamy, R.; Vijayakumar, K. A hysteresis current controller for PV-Wind hybrid source fed STATCOM system using cascaded multilevel inverters. J. Electr. Eng. Technol. 2018. [CrossRef]

14. Balaguer, I.J.; Lei, Q.; Yang, S.; Supatti, U.; Peng, F.Z. Control for grid-connected and intentional islanding operations of distributed power generation. IEEE Trans. Ind. Electron. 2011, 58, 147-157. [CrossRef]

15. Pozzebon, G.G.; Goncalves, A.F.Q.; Pena, G.G.; Mocambique, N.E.M.; Machado, R.Q. Operation of a three-phase power converter connected to a distribution system. IEEE Trans. Ind. Electron. 2013, 60, 1810-1818. [CrossRef]

16. Lee, J.-H.; Jeong, H.-G.; Lee, K.-B. Performance Improvement of grid-connected inverter systems under unbalanced and distorted grid voltage by using a PR controller. J. Electr. Eng. Technol. 2012, 7, 918-925. [CrossRef]

17. Jeong, H.-G.; Kim, G.S.; Lee, K.-B. Second-order harmonic reduction technique for photovoltaic power conditioning systems using a proportional-resonant controller. Energies 2013, 6, 79-96. [CrossRef]

18. Islam, S.U.; Zeb, K.; Din, W.U.; Khan, I.; Ishfaq, M.; Busarello, T.D.C.; Kim, H.J. Design of a proportional resonant controller with resonant harmonic compensator and fault ride trough strategies for a grid-connected photovoltaic system. Electronics 2018, 7, 451. [CrossRef]

19. Teodorescu, R.; Blaabjerg, F.; Liserre, M.; Loh, P.C. Proportional resonant controllers and filters for grid-connected voltage-source converters. Proc. IEEEPA 2006, 153, 750-762. [CrossRef] 
20. Busada, C.A.; Gomez, J.S.; Leon, A.E.; Solsona, J.A. Current controller based on reduced order generalized integrators for distributed generation systems. IEEE Trans. Ind. Electron. 2012, 59, 2898-2909. [CrossRef]

21. Liserre, M.; Teodorescu, R.; Blaabjerg, F. Multiple harmonics control for three-phase grid converter systems with the use of PI-RES current controller in a rotating frame. IEEE Trans. Power Electron. 2006, 21, 836-841. [CrossRef]

22. Castilla, M.; Miret, J.; Camacho, A.; Matas, J.; Vicuna, L.G. Reduction of current harmonic distortion in three-phase grid-connected photovoltaic inverters via resonant current control. IEEE Trans. Ind. Electron. 2013, 60, 1464-1472. [CrossRef]

23. Tran, T.-V.; Chun, T.-W.; Lee, H.-H.; Kim, H.-G.; Nho, E.-C. Control method for reducing the THD of grid current of three-phase grid connected inverters under distorted grid voltages. J. Power Electron. 2013, 13, 712-718. [CrossRef]

24. Yan, Q.; Wu, X.; Yuan, X.; Geng, Y. An Improved Grid-Voltage Feedforward Strategy for High-Power Three-Phase Grid-Connected Inverters Based on the Simplified Repetitive Predictor. IEEE Trans. Power Electron. 2016, 31, 3880-3897. [CrossRef]

25. Zhong, Q.-C.; Hornik, T. Cascaded current-voltage control to improve the power quality for a grid-connected inverter with a local load. IEEE Trans. Ind. Electron. 2013, 60, 1344-1355. [CrossRef]

26. Lv, Z.-K.; Sun, L.; Duan, J.-D.; Tian, B.; Qin, H. Repetitive control with specific harmonic gain compensation for cascaded inverters under rectifier loads. J. Power Electron. 2018, 18, 1670-1682.

27. Teodorescu, R.; Liserre, M.; Rodriguez, P. Grid Converters for Photovoltaic and Wind Power Systems, 1st ed.; John Wiley \& Son: Chichester, UK, 2011; pp. 329-335.

(C) 2019 by the authors. Licensee MDPI, Basel, Switzerland. This article is an open access article distributed under the terms and conditions of the Creative Commons Attribution (CC BY) license (http://creativecommons.org/licenses/by/4.0/). 